Contract Report 522

\title{
Determining the Chemical Composition of Cloud Condensation Nuclei
}

\author{
Second Progress Report \\ Grant Number DE-FO2-90ER61017
}

by Allen L. Williams, Jane E. Rothert, and Kent E. McClure Offices of Precipitation Quality and Atmospheric Chemistry

Darryl J. Alofs, Donald E. Hagen, Daniel R. White, A.R. Hopkins, and Max B. Trueblood Cloud and Aerosol Science Laboratory University of Missouri, Rolla

Sponsored by the U.S. Department of Energy Office of Health and Environmental Research Washington, D.C.

February 1992

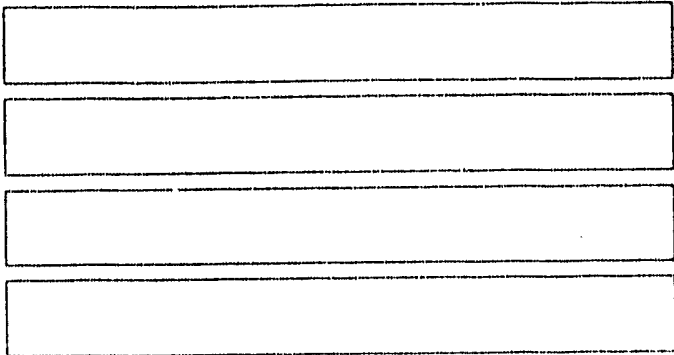

Illinois State Water Survey Atmospheric Sciences Division Champaign, Illinois

A Division of the Illinois Department of Energy and Natural Resources 


\title{
DETERMINING THE CHEMICAL COMPOSITICN OF CLOUD CONDENSATION NUCLEI
}

\author{
Second Progress Report \\ Grant Number DE-FO2-90ER61017 \\ by \\ Allen L. Williams, Jane E. Rothert, and Kent E. MCClure \\ Offices of Precipitation Quality and Atmospheric Chemistry \\ Illinois State Water Survey \\ 2204 Griffith Drive \\ Champaign, IL 61820-7495 \\ and
}

Darryl J. Alofs, Donald E. Hagen, Daniel R. White, A.R. Hopkins, and Max E. Trueblood Cloud and Aerosol Science Laboratory

University of Missouri, Rolla

\author{
Sponsored by the \\ United States Department of Energy \\ Office of Health and Environmental Research \\ Washington, D.C.
}

Allen L. Williams

Principal Investigator

Champaign, Illinois

February 1992 
I. Abstract . . . . . . . . . . . . . . . . . . 1

II. Introduction . . . . . . . . . . . . . . . . . . . 1

III. Continuous Flow Diffusion (CFD) cloud Chamber . . . . . 5

A. Cold Flates . . . . . . . . . . . . . . . . . 5

B. Hot Plate. . . . . . . . . . . . . . . . 8

IV. Preheater. . . . . . . . . . . . . . . . . . . 9

v. Haze Chamber . . . . . . . . . . . . . . . . . . 10

A. Wicking Material Attachment. . . . . . . . . . 10

B. Plate Wetting . . . . . . . . . . . . . . . . . 13

c. system cleanliness . . . . . . . . . . . . . . . . 14

VI. Virtual Impactors . . . . . . . . . . . . . . . . . 17

A. Initial Design . . . . . . . . . . . . . . . 17

B. Improved Design . . . . . . . . . . . . . . . . 20

c. Purge flow Modeling . . . . . . . . . . . . . . . 22

VII. Automated CFD Cloud Chamber . . . . . . . . . . . . . . 24

VIII. Discussion . . . . . . . . . . . . . . . . . 25

Lx. Refererces. . . . . . . . . . . . . . . . . 26

x. Appendix i. . . . . . . . . . . . . . . . . . . 27

XI. Appendix B . . . . . . . . . . . . . . . . . . 38 


\section{Abstract}

This second progress report describes the status of the project orie and one-half years after the start. The goal of the project is to develop the instrumentation to collect cloud condensation nuclei ( $C \mathrm{CN})$ in sufficient amounts to determine their chemical composition, and to survey the CCN composition in different climates through a series of field measurements. our approach to CCN collection is to first form droplets on the nuclei under simulated cloud humidity conditions, which is the only known method of identifying $C C N$ from the background aerosol. Under cloud chamber conditions, the droplets formed become larger than the surrounding aerosol, and can then be removed by inertial impaction. The residue of the evaporated droplets represents the sample to be chemically analyzed. Two size fractions of CCN particles are collected by first forming droplets on the larger $C C N$ in a haze chamber at $100 \%$ relative humidity, and then activating the remaining $C C N$ at 18 supersaturation in a cloud chamber. The experimental apparatus is a series flow arrangement consisting of an impactor to remove the large aerosol particles, a haze chamber to form droplets on the remaining larger CCN, another impactor to remove the haze droplets containing the larger $C C N$ particles for chemical analysis, a continuous flow diffusion (CFD) cloud chamber to form droplets on the remaining smalier $C C N$, and a third impactor to remove the droplets for the small CCN sample. progress is documented here on the development of each of the major components of the flow system. Chemical results are reported on tests to determine suitable wicking material for the different plates. Results of computer modeling of various impactor flows are discussed. The appendices include a paper to be published in the proceedings of the Precipitation Scavenging conference held in Richland, Washington in July 1991, and a paper being submitted to the Journal of Applied

Meteorology.

\section{Introduction}

A schematic of the sampling system is shown in Figure 1. Ambient air is drawn in at a rate of 1332 liters per minute (1pm), which amounts to sampling a cubic volume $4.3 \mathrm{~m}$ on a side in an hour. The system is a aichotomous $C C N$ sampler in that it is designed to separate the $C C N$ into two size fractions corresponding, approximately, to dry particle diametex (D) ranges $D<0.1$ micrometers $(\mu \mathrm{m})$ and $0.1 \mu \mathrm{m}<D<0.5 \mu \mathrm{m}$. It is necessary to collect the smaller particle CCN sample separately, since otherwise any chemical differences as a function of particle size would be masked by the larger particles. Likewise, in order to prevent the CCN composition from being dominated by a relatively few very iarge $C C N$ particles, upon entering the system "the sample passes through the first virtual impactor designed to eliminate particles larger than its cutoff diameter of $0.5 \mu \mathrm{m}$. 
$1333 \mathrm{LPM}$
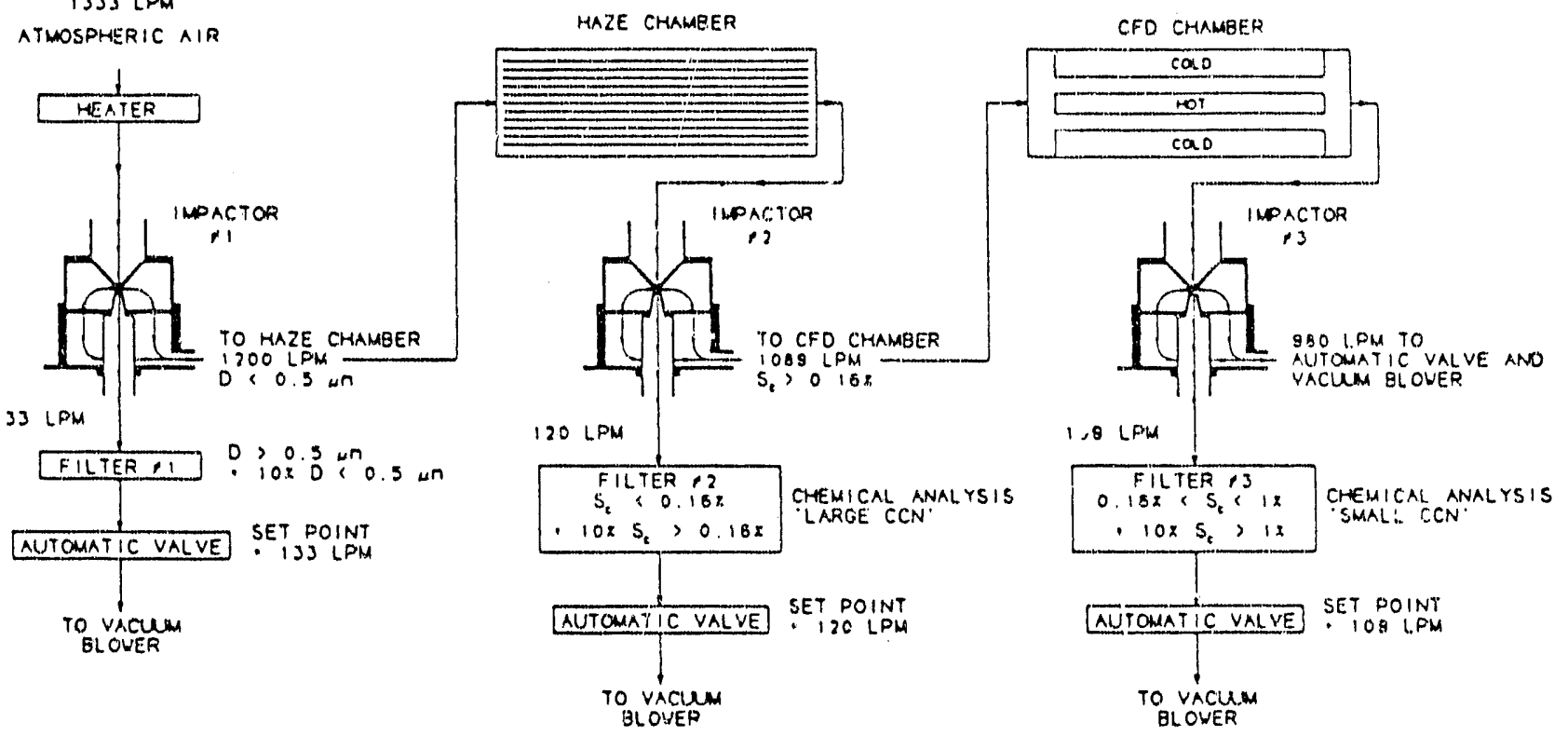

Figure 1. Flow diagram of $\mathrm{CCN}$ collection systam.

Although the limits of these different size ranges are somewhat arbitrary, the design does address the important question of differences in $C C N$ composition with particle size.

Since the incoming air is heated, the air and aerosol $<0.5 \mu \mathrm{m}$ leaving the first impactor remains heated. The incoining air temperature is set so its wet bulb cemperature is the desired opexating temperature of the haze and CFD chambers. The haze chamber consists of wetted parallel plates of $1 \mathrm{~cm}$ separation, between which the air passes in a parallel flow arrangement. since the plates are wetted, and the incoming air temperature is set, the plates and air should stabilize at the wet bulb

temperature while the air comes to $100 \%$ relative humidity. The sample resides in the haze chamber for approximately 25 seconds, enabling the soluble haze particles to deliquesce and reach their equilibrium size. This size can uniquely be related to a critical supersaturation, $S_{c}$, at: which the corresponding $C C N$ would be activated. Those droplets with an equilibrium size $>0.5 \mu \mathrm{m}$, corresponding to $S_{\text {. }}<0.16 \%$, are removed from the aerosol stream in the second virtual impactor placed immediately following the haze chamber. This represents the largest of the two CCN size classes obtained. If the $C C N$ were $50 \%$ by volume ammonium sulfate, the condition $S_{c}<0.16 \%$ would correspond to $D>0.1 \mu \mathrm{m}$.

The aerosol passing through the second virtual impactor, and into tise CFD cloud chamber, should have a haze droplet diameter <0.5 $\mu \mathrm{m}$, which would correspond to $D<0.1 \mu \mathrm{m}$. The CFD cloud chamber operating at 1 s supersaturation should activate $C C N$ down to sizes as small as $0.03-\mu \mathrm{m}$ dry diameter. Once activated, the droplets. 
undergo rapid diffusional growth, reaching a diameter of about $3.5 \mathrm{~mm}$ during the total residence time of almost 5 seconds in the CFD cloud chamber.

The droplets are then removed by the third virtual impactor operating at a cutoff diameter of $1 \mu \mathrm{m}$. The coarse flow section of this impactor, into which the particles $>1 \mu \mathrm{m}$ are collected, is to be operated at a zero net coarse flow. The collected particles simply concentrate in the collection cup. Contamination from the background aerosol should be very low compared to a conventional virtual impactor in which a portion of the total flow containing fine particles is drawn into the coarse flow collection. From here, one possibility is to permit the CCN to remain in the collection cup where they would eventually attach to the walls. The collection cup itself would then be removed, and the $C C N$ sample washed from its inside surface for analysis. Present plans, however, are to continually remove the sample inside the collection cup onto a filter by introducing a purge flow.

Two identical versions of the sampling system are being built. Figure 2 shows the laboratory version of the haze and CFD cloud

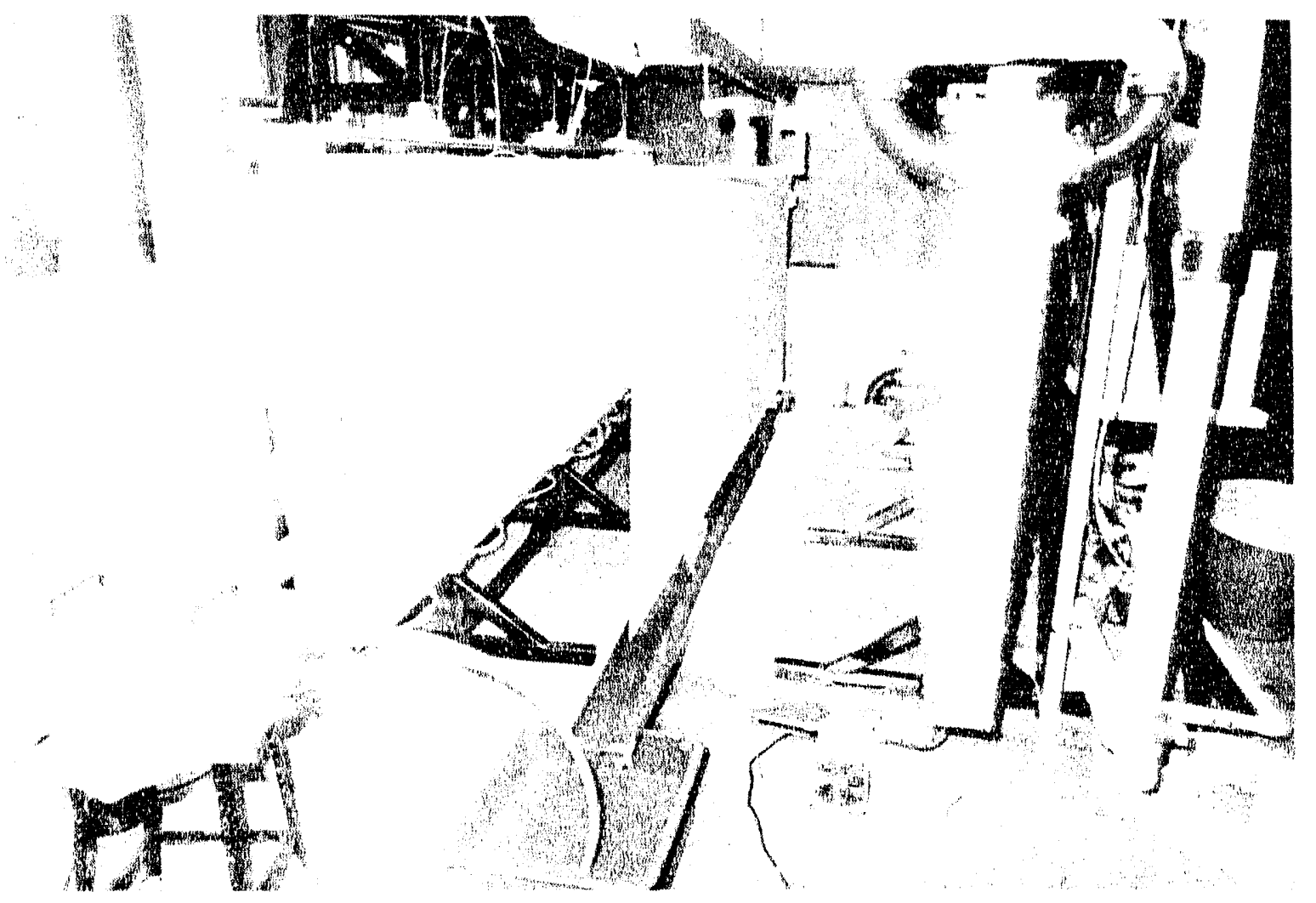

Figure 2. View of the haze chamber (1eft) and CFD cloud chamber (right). 
chambers at their present stage of construction, and Figure 3 shows one of the three virtual impactors. The haze chamber is on the stand at the left foreground of Figure 2. The inlet manifold, onto which the first impactor is to be placed, can be seen attached at the end of the haze chamber frame, and one of the 11 haze chamber plates is hanging in the center of the picture above a trough that drains the plate-wetting water for testing purposes. When assembled, the haze chamber would of course be completely enclosed by aluminum plates attached to the frame, and both it and the CFD cloud chamber covered by insulation.

The CFD cloud chamber is on the stand at the right of the picture. Equipment partly visible to the right of the CFD cloud chamber is for temperature regulation and pumping of the water that is to control the cold plates of the CFD cloud chamber. The cooling water enters the CFD cloud chamber through the attached 4-inch (4") diameter pipes (bottom background of Figure 2), and leaves through similar pipes attached to the top (foreground). Sample air enters through the haze chamber manifold, transits the

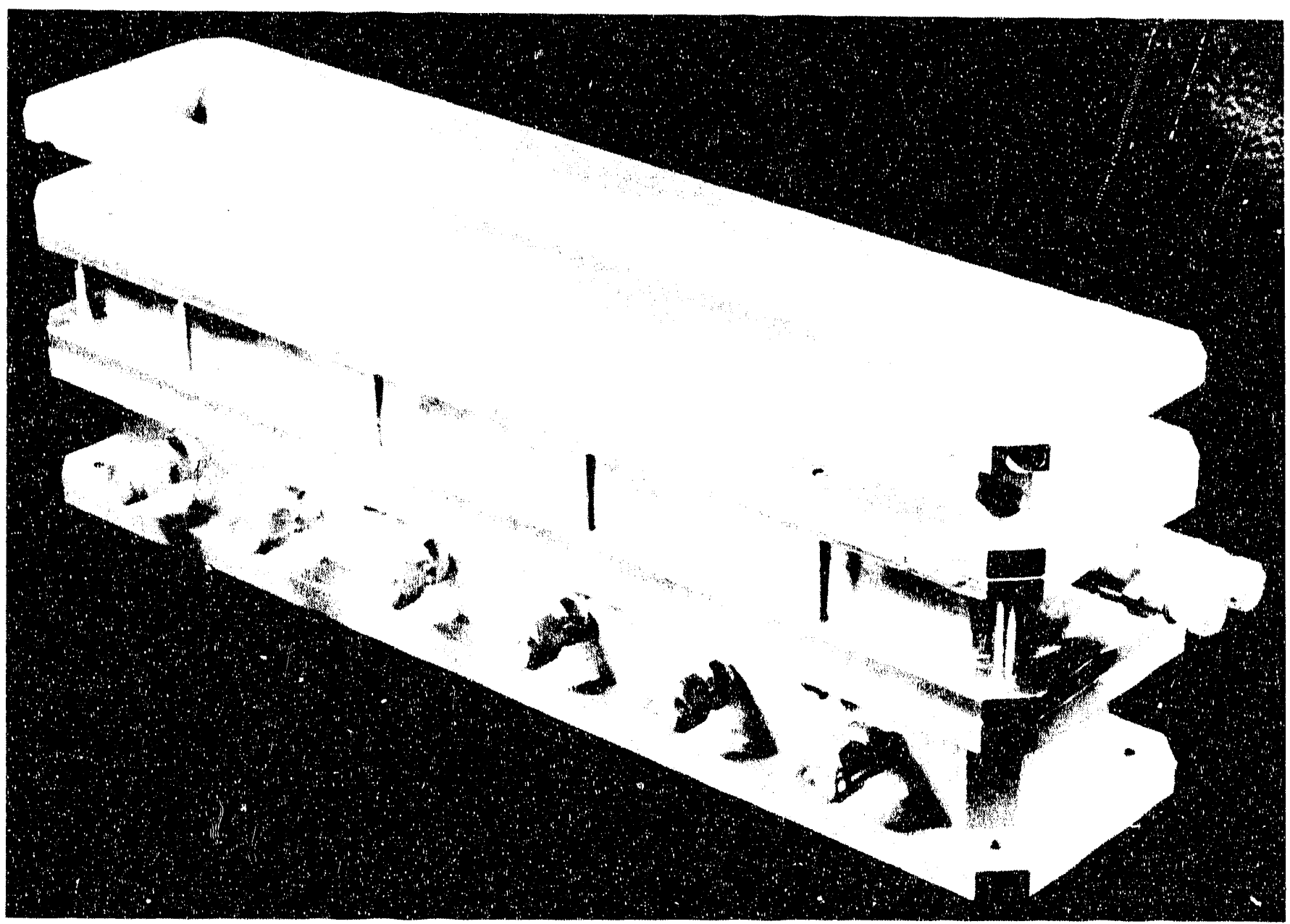

Figure 3. View of inertial impactor. 
12-foot $\left(12^{\prime}\right)$ length of the haze chamber, exits at the far end through an impactor, then enters the CFD cloud chamber at the far end and exits the CFD cloud chamber through the third impactor that will be attached to the end of the CFD cloud chamber (foreground).

The virtual impactor shown in Figure 3 has dimensions 14 " $x$ $3.5 " \mathrm{x}$ " ". As it is positioned in the picture, air would enter through the top and flow downward. The fine flow exits through the bottom of the base. The coarse flow exits through the series of six connectors positioned horizontally along the base. All three of the impactors will have the same general construction, with the difference in their cutoff size determined by changing the slit widths.

The constant consideration that such a complicated system must be operated in the field under a wide variety of conditions accentuates the importance of otherwise minor details. Failure in the adhesion of the wetted cloth material to the underlying aluminum plates, or the CFD cloud chamber hot-plate heaters, for example, would necessitate opening either the CFD cloud chamber or haze chamber under field conditions. Although the trailer is being equipped with an overhead crane to move the heavier parts, and support them during maintenance, considerable attention is being given to anticipating problems in order to produce a lowmaintenance system.

\section{Continuous Flow Diffusion (CFD) Cloud Chamber}

A diffusion cloud chamber operates by maintaining wetted surfaces a fixed distance apart, and at a fixed temperature difference. The desired $1 \%$ supersaturation can only be achieved by precise temperature control of the plates to an accuracy of under $0.1^{\circ} \mathrm{C}$. In the present design, the two outside cold plates are both water-cooled to the same temperature. An electrically controlled hot plate, maintained at the same warm temperature on both its surfaces, is placed between the cold plates to form two diffusion chambers that will operate in a parallel flow arrangement. only the hot-plate surfaces are wetted by an external water supply, since condensation at the lower temperature will keep the cold p.lates wet.

\section{A. Cold plates}

The two cold plates of the CFD cloud chamber are to be thermostatted at $20^{\circ} \mathrm{C}$, the hot plate at $25^{\circ} \mathrm{C}$. The cold plates are 2 inches thick, and are oriented vertically with dimensions 12 feet long by 4 feet high. The plates are hol.low, and 50 gallons per minute (gpm) of thermostatted water is pumped through each plate. Internal manifolds and baffles inside the cold plates channel the flow to uniformly distribute the heat. Figure 4 shows 


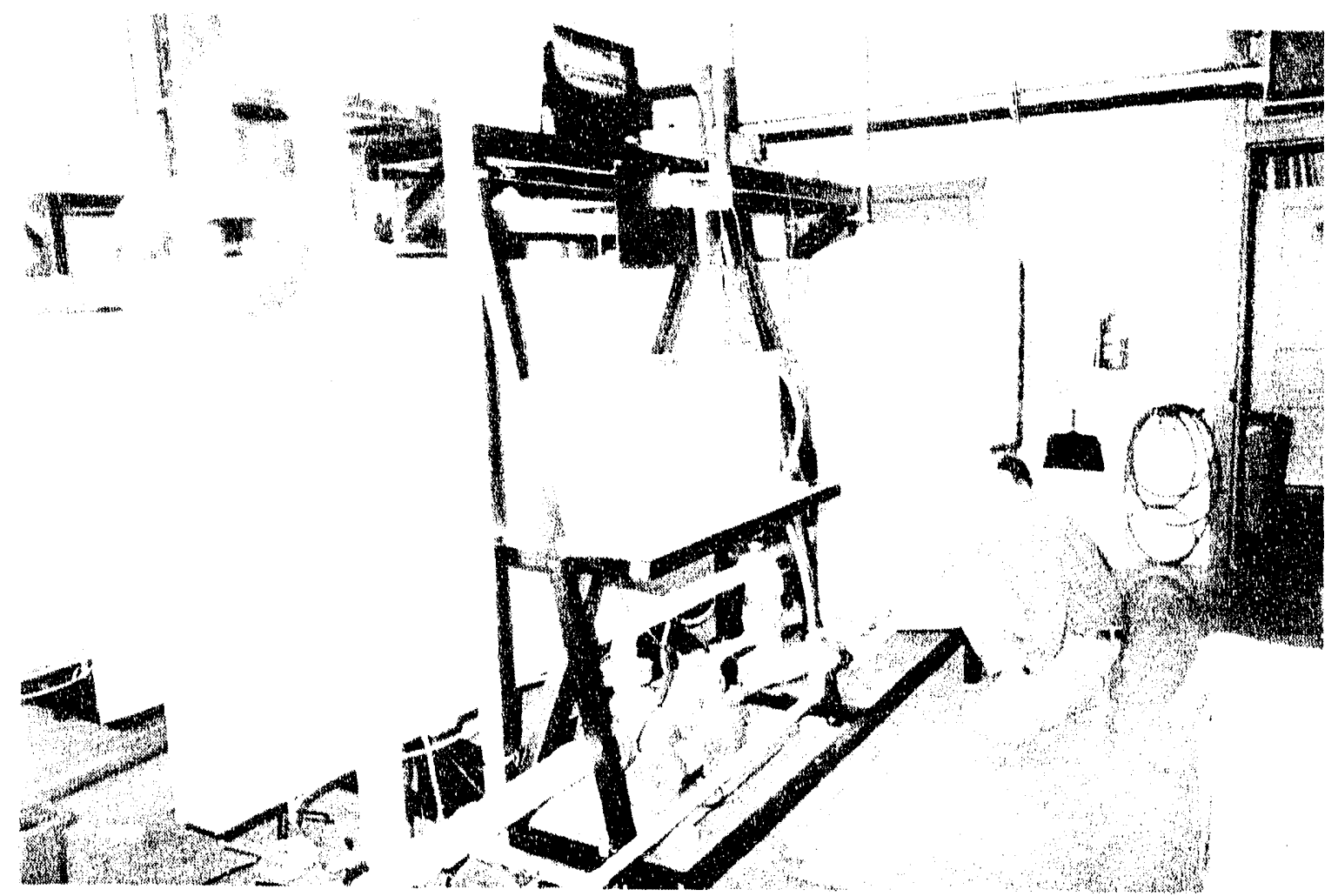

Figure 4. CFD cloud chamber cold-plate thermal control system.

an external view of the cold plates with the equipment to thermally control and distribute the water. The larger of the two pumps on the floor circulates $100 \mathrm{gpm}$ through the main water loop from the water tank in the background, through the 4-inch diameter water lines to the cold plates, and back to the reservoir. The main water loop has an electric heater, which is cycled on and off by a controller to stabilize the cold-plate temperature. The smaller pump circulates water through the chiller, visible on the shelf above the pumps, which ties into the main water loop to provide cooling. It is necessary to continually cool the water, or the system would drift to higher temperature from heat inputs of the room and the pumps. Since heaters respond much faster than chillers, the water is continually cycled through the chiller, and the final temperature regulation is achieved by the heater controller system.

Test results of the cold-plate temperature at different positions are shown in Figure 5. The dotted lines indicate the positioning of the manifold system inside the cold plates. Water enters at the lower left-hand corner and flows to the right along the bottom, with part of the flow diverted upward through each of the vertical channels, then to the outlet. The numbers on Figure 5 are temperature differences measured in degrees centigrade, and their position corresponds to the approximate position on the plate where the temperatures were read. Numbers with an FB 
notation near them indicate the temperature difference between the two cold plates at that particular location. Numbers without the FB designation represent differences between the local plate temperature and the mean plate temperature. In these tests the hot plate was not installed inside the CFD cloud chamber nor was the chamber insulated. The heat load of the electric heaters was approximately simulated by cooling the cold plates to $13^{\circ} \mathrm{C}$. The cooling capacity has been found to be adequate, and the spatial temperature uniformity is within $0.05^{\circ} \mathrm{C}$ as shown in Figure 5 . This excellent temperature uniformity is achieved due to the large water flow, and the uniform circulation of water to all regions of the cold plates.

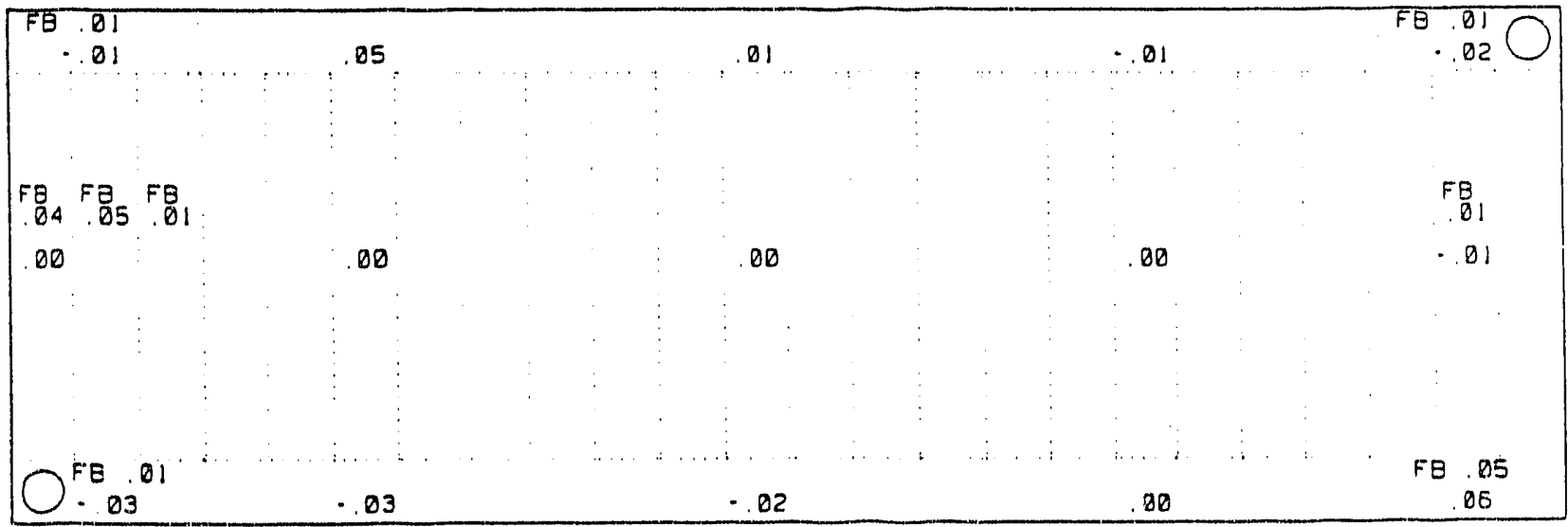

INLET

Figure 5. Cold-plate temperature variations.

In order to withstand the high pressure of the water circulation system, the outer skin of each cold plate is fastened with hundreds of screws. The screws are attached into holes that have been threaded into either the CFD cloud chamber frame, or to the aluminum baffles inside the cold plates, and pass through special washers containing rubber seals to prevent leaks. The inside surface of the cold plates are spot-welded to the baffles. The hot plate is to be positioned between the cold plates with a grid of rigid spacers on both sides of the hot plate to position the hot and cold plates at $1-\mathrm{cm}$ spacing. This also lends additional support to the inner cold plate surfaces, which must withstand the pressure difference of the water circulation on one side and the low pressure of the air flow system on the other. 


\section{B. Hot Plate}

As mentioned above, the hot plate is placed between the cold plates, and spaced $1.0 \mathrm{~cm}$ from each of the cold plates in the CFD cloud chamber. It is heated by 24 commercial heaters each in the form of a sheet about 4 feet by 6 inches. The heaters axe sandwiched between two rubber sheets, which are sandwiched between two aluminum plates. The entire structure is held together by screws located on a 6-inch by 7.5-inch rectangular grid. Figure 6 shows the hot plate with one aluminum plate removed, and with a portion of a rubber sheet rolled back to reveal four of the electric heaters. The grid of white dots on the rubber sheets is the bushings used to make a watertight seal around the screws, which hold the sandwich together. These bushings, custom-made for this application, consist of an elastomer cylinder inside a shorter aluminum cylinder. Careful design went into producing a reliable hot plate, which is unlikely to experience failure in the field.
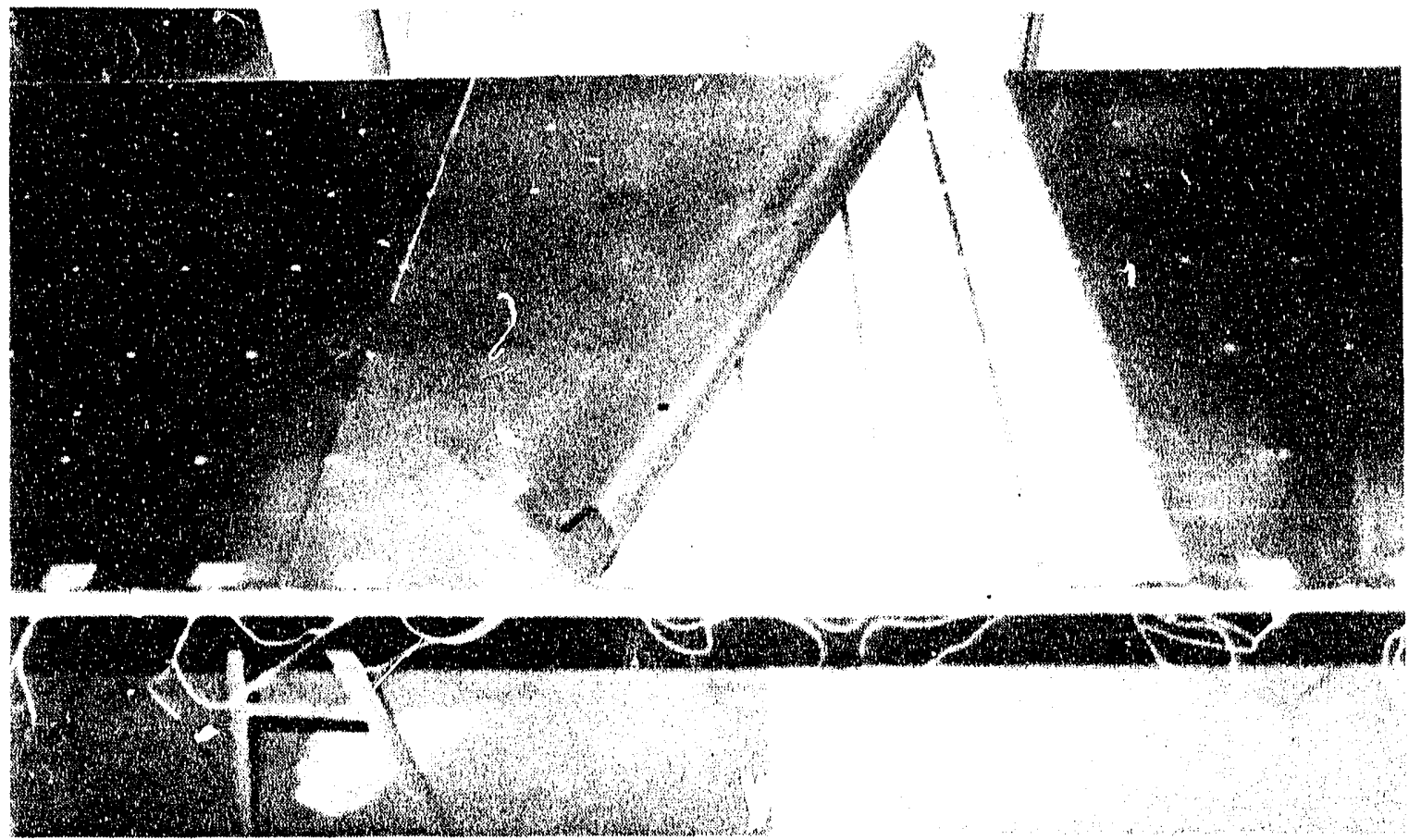

Figure 6. Internal view of hot plate.

The view of the CFD cloud chamber shown in Figure 7 shows the control system for the hot-plate temperature. The researcher in this figure (Max Alcorn) has his hand near the control panel of the hot plate. The 12 round knobs on this panel allow individual adjustment of each pair of heaters in order to obtain an approximately isothormal hot plate. Thermal resistors will be installed to monitor the performance of each heater. Active computer control of the heater temperature is not necessary, 
since the temperature should remain constant and require very little adjustment. The mathematical model of the CFD cloud chamber indicates that the watt density variations required are well with the capability of the heaters. If the CFD cloud

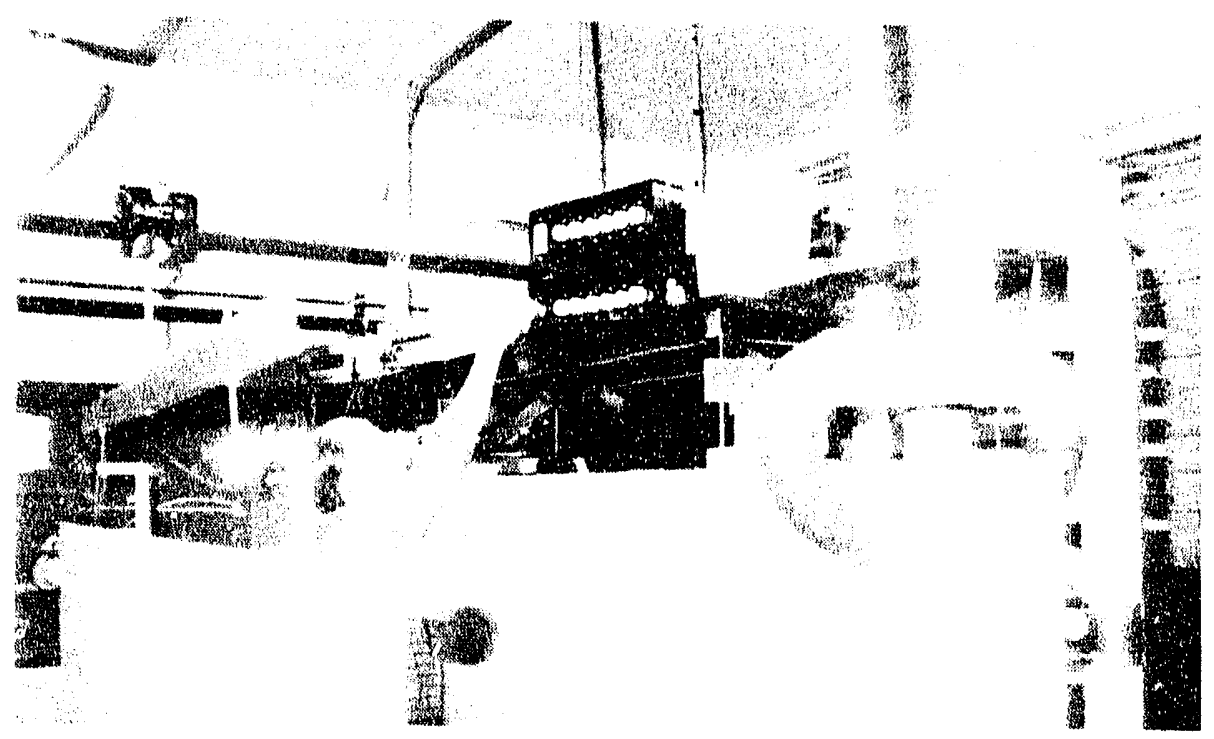

Figure 7. Hot-plate temperature control system. chamber inlet sample temperature were considerably different than the wet bulb temperature of the hot plate, much more heating capacity would be required.

\section{Preheater}

Placing a preheater upstream of the haze chamber to heat the incoming air, regardless of its humicity, to the wet bulb temperature of the CF'D cloud chamber hot plate, controls the haze chamber temperature without costly external thermal control, and lessens the CFD cloud chamber hot-plate heating capacity requirement. The preheater (Figure 8 ) raises the temperature of the incoming atmospheric air such that the haze chamber operates at close to room temperature. The heater of the CFD cloud chamber must operate at the same temperature as the liaze chamber, otherwise the heat flux at the leading edge of the hot plate becomes so high that it exceeds the capacity of the electric strip heaters inside the hot-plate. Also, it is important that the preheater be able to respond quickly to changes in atmospheric conditions to maintain the wet bulb temperature of the air coming out of the preheater close to $25^{\circ} \mathrm{C}$. The time constant to change the temperatures of the cloud chambers is too long to track changes in atmospheric conditions.

Figure 8 shows the preheater. The horizontal cylinder (top of photo) is a stainless steel shell-and-tube heat exchanger with air as the shell fluid, and heated water as the tube fluid. The water is circulated by a pump (seen on the floor) in a closed loop through both the heat exchanger and an immersion electric 
heater (contained in the shorter horizontal.

cylinder seen jist below the heat exchanger). The electric heater is cycled on and off by a

temperature controller. The preheater systam has been tested and works well, with a time response of about 3 minutes, which is adequate.

\section{Haze Chamber}

The haze whamer is seen on the left side of Figure 2. The six cylinders arranged along a vertical line are part of the inlet manifold. Tre air passing through these tubes will be at a dry bulb

temperature as high as $75^{\circ} \mathrm{C}$ to produce a wet bulb temperature of $25^{\circ} \mathrm{C}$ for a wide range of atmospheric relative humidities. The hot air passing across the wet plates cools them by water evaporation, and the

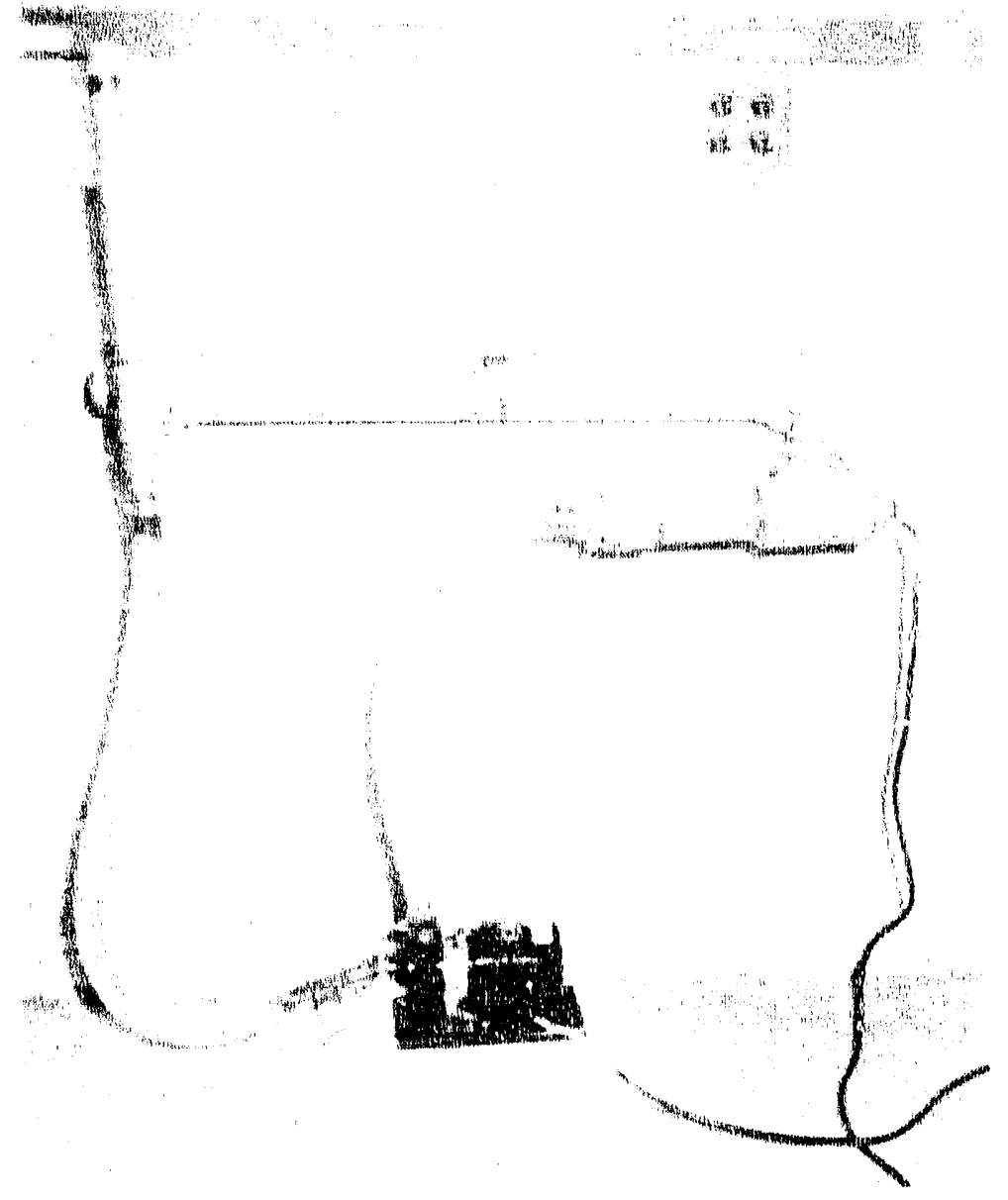

Figure 8. Inlet air preneater. air adjacent to the plates is cooled and humidified by convective heat and water vapor transfer from the plates. The air temperature approaches the wet bulb temperature of the plates, while the humiaity approaches 100\%. Calculations show the plate temperature to be nearly isothernal. The wet bulb temperature of the incoming air is brought to $25^{\circ} \mathrm{C}$ so that the wet plates inside the haze chamber will also be at $25^{\circ} \mathrm{C}$. Any wet surface that the sample air comes in contact with will tend to be cooled to $25^{\circ} \mathrm{C}$ by evaporation. Dry surfaces, such as the inside of the inlet manifold, will be dry and therefore hot. The six cylinders of the inlet manifold are constructed of two thin-walled stainless steel tubes, with an air gap between them, to minimize heat. transfer from the air sample to the frame of the haze chamber.

\section{A. Wicking Material Attachment}

The respective $12^{\prime} \times 4^{\prime}$ vertical surfaces, which must be kept wetted, consist of both sides of the 11 internal plates of the haze chamber and the CFD cloud chamber hot plate, as well as the 
single sides of the haze chamber outer walls and the CFD cloud chamber cold plates. The wetting should be uniform over the entire surface with a visible film of water that makes a shiny wet appearance. This is achieved by surplying water at the top edge of each plate (with the exception of the CFD cloud chamber cold plates, which are wetted by vapor condensation), and by covering both surfaces of each plate with a wicking material. Without the wicking material, the water would flow down the plates in rivulets, rather than as a uniform, thin layer. The alternative, covering the plates with sintered aluminum, and pumping water at high pressure through the porus material to wet the surfaces, is impractical due to the high cost of the large amount of sintered material necessary.

The wicking material must be very water adsorbent, and remain so after several wet-dry cycles. Since the field version of the equipment will be moved in a trailer, the material must be strong enough to withstand the vibrations from traveling on the road. The material must be absolutely clean, as traces of contaminants from the walls could dominate the sample composition. Although filter paper is a common wicking material for cloud chambers, it would be unsuitable for the present application, because it would tear under its own weight if paper were to pull away from the plate. Adhesives were initially considered to glue the wicking material to the plates, but this approach was eventually

abandoned because of fear that the adhesive would be a source of chemical contamination of the $C C N$ sample. The wicking material finally chosen after investigating many alternatives was cotton cloth; similar to that used for bedsheets. Enough cloth for both versions of the apparatus was purchased from the same batch, since slight variations in the product occur over time. From the standpoints of strength, adsorbent ability, and tests of cleanliness, the material chosen is adequate.

Figures 9-1.1 show details fo the haze chamber plates. The cloth material must be attached to the plates to maintain, in each case, the $1-\mathrm{cm}$ plate spacing. Although the peak supersaturation between wetted plates does not vary as the plate separation is decreased, there is a danger when the wicking material pulis away from one of the plates. In the case of the haze chamber, if the cloth dries slightly as it pulls away, it would lose some evaporative cooling and become warmer. There would then be a temperature difference between the plates potentially making a small supersaturated region. A wrinkle in the wicking material on a CFD cloud chamber plate would tend to decrease the supersaturation in its vicinity. The affected area could lose thermal contact with the plate, thus decreasing the temperature difference, and consequently the supersaturation between plates. If the wrinkled area were to become dry, the supersaturation would also naturally decrease. 
In order to achieve a suitable fit, the

cotton cloth is first pre-shrunk by machine washing and drying at a moderately hot temperature setting. If, during operacion, the wetting system of the haze chamber would fail, the haze chamber plates would dry and approach the incoming air temperature riear $75^{\circ} \mathrm{C}$, so preshrinking to this temperature is advisable. For a haze chamber plate that must have the wicking material on both sides, rod pockets are sewn into an $8^{\prime}$ $x 12$ ' piece of cloth on both $12^{\prime}$ edges and one of the $8^{\prime}$ edges. Small

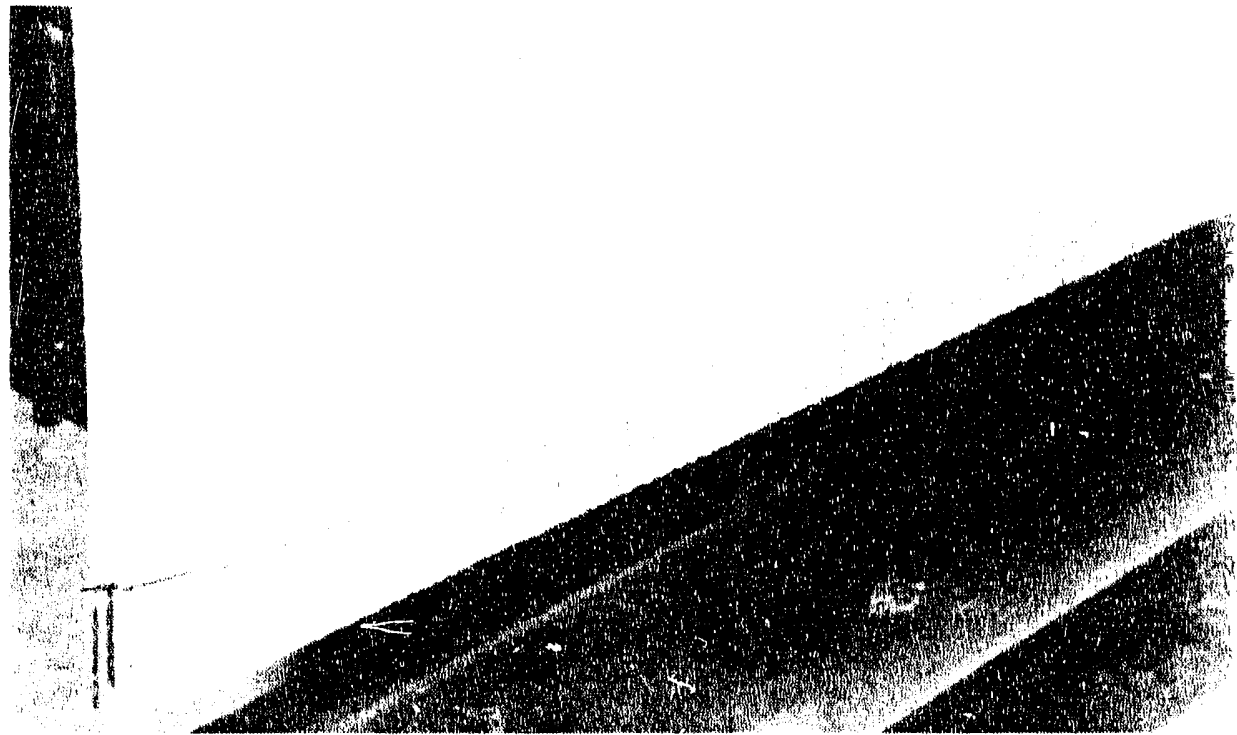

Figure 9. cloth attachment to bottom of haze chamber plate.

1/16" diameter

aluminum rods are placed inside the rod pockets

analogously to the preparation for hanging curtains with curtain rods. The cloth is then folded in half along the 12' length, and the 4' edges on one end are sewn together. The cloth is then slipped over the $12^{\prime} \times 8^{\prime}$ haze chamber plate with the pre-sewn ve:-tical edge at the inlet end of the chamber. The material is then stretched and sewn in place, first along the downstream vertical edge, then along the bottom edge of the plate as shown in Figure 9. The strip visible along the bottom edge of the plate in Figure 9 that is not covered with cloth will be 
submerged in water.

\section{B. Plate Wetting}

In order to uniformly

distribute the water along the 12 ' length of plates, silicone rubber tubing is mounted along the top edge of each plate using stainless steel. clips shaped somewhat like cotter keys as shown in Figure 10. Holes are cut in the tubes starting with a $1^{\prime \prime}$ spacing at the flow inlet, and with decreased spacing along the length of the tube. A special knife was designed to make these holes, which are in the form of slits 1/16" long. When water is supplied to the tubing at a pressure of 3 pounds per square inch, the slits open up and allow the correct water flow to pass through them. The tubing was originally glued to the top edge of the plates, but this was replaced with

stainless steel clips in order to avoid chemical contamination.

Figure 11 shows a plate with the water turned on. Note that the cloth is a iairly uniform grey tone, because, being uniformly wet and in contact with the aluminum plate, it takes on the greyness of the aluminum. When the cloth is dry, it is snow white, the color of the four styrofoam blocks seen on the floor. Achieving the uniform wetness seen in Figure 11 took many months of trialand-error procedures.

If the water is turned on while the cotton cloth is dry, it tends to run down the plates faster in some places than others. The condition usually persists until the water is turned off. Uneven wetting can also result in islands on the cloth where air is trapped between the cloth and the aluminum plate. Although 
surface tension tends to force the air out, it cannot pass through the wet cloth, so air bubbles become trapped under the cloth. Once formed, the air bubbles remain indefinitely. A solution to this problem is to slowly flood the entire cloud chamber from the bottom while the cloth is still dry, forcing the air upward and from behind the cloth as the water level rises. once the chamber has been flooded, the water supply at the top of the plates is turned on, and the water that flooded the chamber is slowly drained out at the bottom. No air bubbles are formed behind the cloth using this technique.

\section{c. system cleanliness}

Since the ambient $C C N$ mass concentrations are so low, contamination from the surfaces of the collection system is an important issue. The number of different materials that the sample air comes in contact with are kept to a minimum, and all aluminurn plates and surfaces are anodized. The wetting system, including the wicking material and the wetting water, represents a potential source of contamination.

The water tiat runs down the plates of the cloud chambers is drained to a common reservoir, passed through a cleanup system, and recirculated. The cleanup system is designed to remove ary waterborne contaminants that are leached from the interior of the cloud chambers, or are introduced from the air stream. The water passes through a variable flow rate vane pump, then through a $10 \mu \mathrm{m}$ filter, then through an adsorption column that removes most organic compounds, free chlorine and chloramines, phosphate complexes, and turbidity. Two deionizing columns operated in tandem remove all ionizable solids. Finally, the water is filtered with a $0.2 \mu \mathrm{m}$ absolute filter to remove any remaining particulate. When operated in the open air with no particular care concerning cleanliness of the collection reservoir or the cloth and plates, the system produced water with a resistivity of 17 megohms $/ \mathrm{cm}^{3}$, which is judged to be adequate performance. During operation of the $C C N$ sampling system, samples of the wetting water will be routinely analyzed and compared with the CCN composition.

Several different wetting materials were tested as part of the process to decide which wicking materials to use, and to determine the expected level of contamination from the wicking material. A device was built (Figure 12) to simulate the action of a cloud chamber with respect to the wetting water and wicking material. The overall dimensions of the device is $23 \mathrm{~cm} \times 63 \mathrm{~cm}$. Deionized (DI) water enters the tube at the top rignt, passes into the individual water feeds of the ten different chambers, flows over the wicking material in each compartment, and is collected in bottles at the outlet of each compartment. The device is made from aluminum with a plexiglass front. The ten 
chambers were used to study four different types of wetting materials, in duplicate, plus two chambers for blanks. Each chamber was thoroughly rinsed with DI water prior to placing the wetting material in the chambers. The materials were all handled only with gloves that had been previously rinsed and then soaked in DI water.

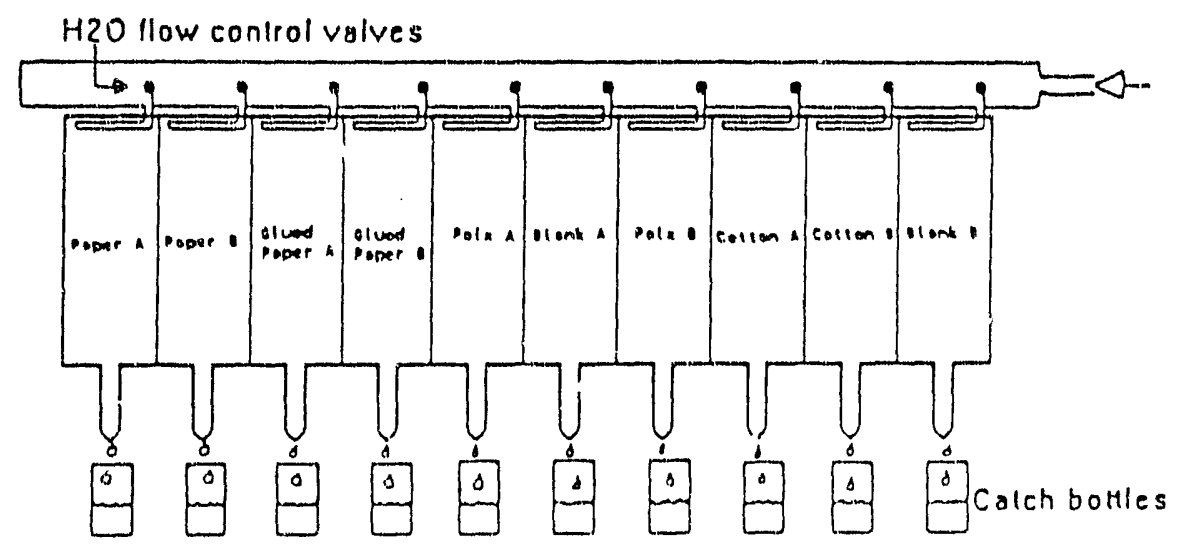

Figure 12. Device to test contamination of wicking materials.

Table I. Concentrations (ppm) of Tons rashod from Different Wicking Materials

The test results given in Table 1 are for the following materials:

1) Filter paper: The paper was removed from a large sheet and is of the type often used in cloud chambers.

\section{2) Filter paper} glued to muffled aluminum foil: The same paper as above but glued to cleaned, muffled aluminum foil using Pliobond ${ }^{R}$ General Purpose Adhesive, T.M. Ashland Oil, Inc., packaged and marketed by W.J. Ruscoe Co., Akron, $\mathrm{OH}$.

\begin{tabular}{|c|c|c|c|c|c|c|c|}
\hline Datelion & $F$ & $\mathrm{Cl}$ & $\mathrm{NO} 2$ & $\mathrm{Br}$ & No3 & 804 & so4 \\
\hline \multicolumn{8}{|l|}{ Paper } \\
\hline 17JUN91 & 0 & 1.77 & 0 & 0 & 0.202 & 0 & $>2.0$ \\
\hline 17 JUN31 & 0 & 0 & 0 & 0 & 0 & 0 & 0.547 \\
\hline 18JUN91 & 0 & 0 & 0 & 0 & 0 & 0 & 0 \\
\hline 20JUN9 1 & 0 & 0 & 0 & 0 & 0 & 0 & 0 \\
\hline 25JUN91 & 0 & 0 & 0 & 0 & 0 & 0 & 0 \\
\hline \multicolumn{8}{|c|}{ Paper + Glue } \\
\hline 17JUN91 & 0 & 1.143 & 0 & 0 & 0.15 & 0.0375 & $>2.0$ \\
\hline 17JUN91 & 0 & 0.905 & 0 & 0 & 0 & 0.41 & $>2.0$ \\
\hline 18.JUN91. & 0 & 0 & 0 & 0 & 0 & 0 & 0.057 \\
\hline 20JUN9L & 0 & 0 & 0 & 0 & 0 & 0 & 0.0242 \\
\hline 25JUN91 & 0 & 0 & 0 & 0 & 0 & 0 & 0.01 \\
\hline \multicolumn{8}{|l|}{ POLX } \\
\hline 17 JUN9 1 & 0 & 0.025 & 0 & 0 & 0 & 0 & 0.0175 \\
\hline 17JUN9I & 0 & 0 & 0 & 0 & 0 & 0 & 0 \\
\hline I 8.JUN9 I & 0 & 0 & 0 & 0 & 0 & 0 & 0.026 \\
\hline 20JUN91 & 0 & 0 & 0 & 0 & 0 & 0 & 0 \\
\hline 2SJUN9I & 0 & 0 & 0 & 0 & 0 & 0 & 0 \\
\hline \multicolumn{8}{|l|}{ Cotton } \\
\hline 1.7JUN9L & 0 & $>2.0$ & 0.028 & 0.0078 & 0 & 0.0838 & $>2.0$ \\
\hline 17,3 UN91 & 0 & $>2.0$ & 0 & 0 & 0 & 0.046 & $>2.0$ \\
\hline $18 . J 11 N 91$ & 0 & 0 & 0 & 0 & 0 & 0 & 0.015 \\
\hline 20JUN91 & 0 & 0 & 0 & 0 & 0 & 0 & 0.016 \\
\hline 25 JUN91 & 0 & 0 & 0 & 0 & 0 & 0 & 0 \\
\hline
\end{tabular}


3) Cotton cloth: 100\% cotton cloth, bleached, obtained from Fancock rabrics. This is a sample of the material that is to be isod in the $C C N$ experiments.

4) Poix: Super Polx 1200 is a precleaned polyester material obtained from Berkshire Corp., Great Barrington, MA, for use in laboratory clean rooms. This material was very adsorbent at first, and is manufactured under strict control. (It became almost non-wettable after repeated wetting.)

The flow of DI water ( 18 megohms $/ \mathrm{cm}^{3}$ ) was adjusted in each individual chamber to mimic the flow expected in a cloud chamber. The first sample fraction was collected as soon as the 60milliliter $(60-\mathrm{ml})$, cleaned polyester bottles were filled. The second fraction was collected 8 hours after water was first started through the system. The third fraction was collected after 24 hours of continual rinsing. The fourth fraction was collected 3 days after the start of rinsing and the fifth fraction was collected 8 days after continual rinsing of the cloud chambers.

The results of the analysis by ion chromatography (IC) are in Table 1. Zeros in the table refer to concentrations below the detection limit. Values in the table are averages of the duplicate samples. Both blanks were below detection limits for each compound. It is clear that each material became cleaner as more water was flushed through it. Even the glued paper became clean, although tests for inorganic compounds, which were not made on these samples, would need to be included before the glue could be trusted.

Results from a similar study to determine the suitability of using silicone rubber tubing to distribute the watex to the top edge of the wetted plates is in progress, and some preliminary results are available. The procedure was to first flush an 18 " length of the tubing for an hour, and discard the solute. The tube was then flushed with 40 liters of DI water over a 23-hour period, to simulate the use of the tubing in the wetting water delivery systern, and a sample of that solute analyzed by IC. In this case the values were all below detection limits. Another piece of the tubing, after pre-soaking for 1 hour in DI water, was soaked in DI water for 23 hours, and a sample of the solute did show some contamination. It remains to be determined whether that contamination is a result of handling, or if it is actually leached from the silicone tubing. 
VI. Virtual Impactors

A. Initial Design

The first impactor built is shown in Figures 13 and 14. Figure 13 shows the internal view of the impactor when the two halves have been separated. Figure 14 shows the external view of the impactor with one of the cover plates removed from the fine flow region. The two similar halves fit together on the lightly shaded, flat surfaces with the bolt holes shown in Figure 13. The critical spacing of the $0.040 "$ inlet slit, and the $0.060 "$ coarse flow slit are formed as the two halves are bolted tcrether. Considering the bottom picture of Figure 13, the inlet is at the top. Half of the fine-particle flow turns and passes into the slit visible near the top of this picture, which is immediately after where the irilet slit is formed when the two halves are joined. This part of the fine flow then exits through the series of 24 holes along the bottom of the impactor half. The region between the visible slit and the fine flow exit is the coarse flow cup.

One purpose of this design was to test the idea of a purge flow impactor, in which the net coarse flow is zero, and a clean air stream is introduced to flush the sample from the coarse flow cup. Again referring to the bottom picture of Figure 13, the purge flow entered through the connectors at the left end of the impactor, and passed into a channel that exterds the entire width of the coarse cup. The purge air entered the cup through a slit along the length of this channel into the cup region. During the course of experimentation deflectors were variously placed over the inlet slit to allow the purge flow to enter at different positions inside the cup. The purge sample exited the cup at the right side of the cup opposite the inlet connector.

The purge coarse flow design of this impactor did not work: satisfactorily. As soon as the impactor flo' started, the clean purge air became contaminated with particles smaller than the cutoff size from the inlet flow. The most convincing hypothesis to explain the results was that slight pressure fluctuations along the 12" length of the impactor inlet introduced small particles into the cup. Such a process would not necessarily alter the impactor cutoff and would hardly be noticed if even a small coarse flow were permitted. An impactor cup that is presently being tested has several partitions in the cup region to reduce any organized cross flows.

Most virtual impactors that have been developed use circular jets. However, the rectangular geornetry is best for our application, because it allows less disturbance of the flow pattern at the exit of the cioud chambers. In developing the 

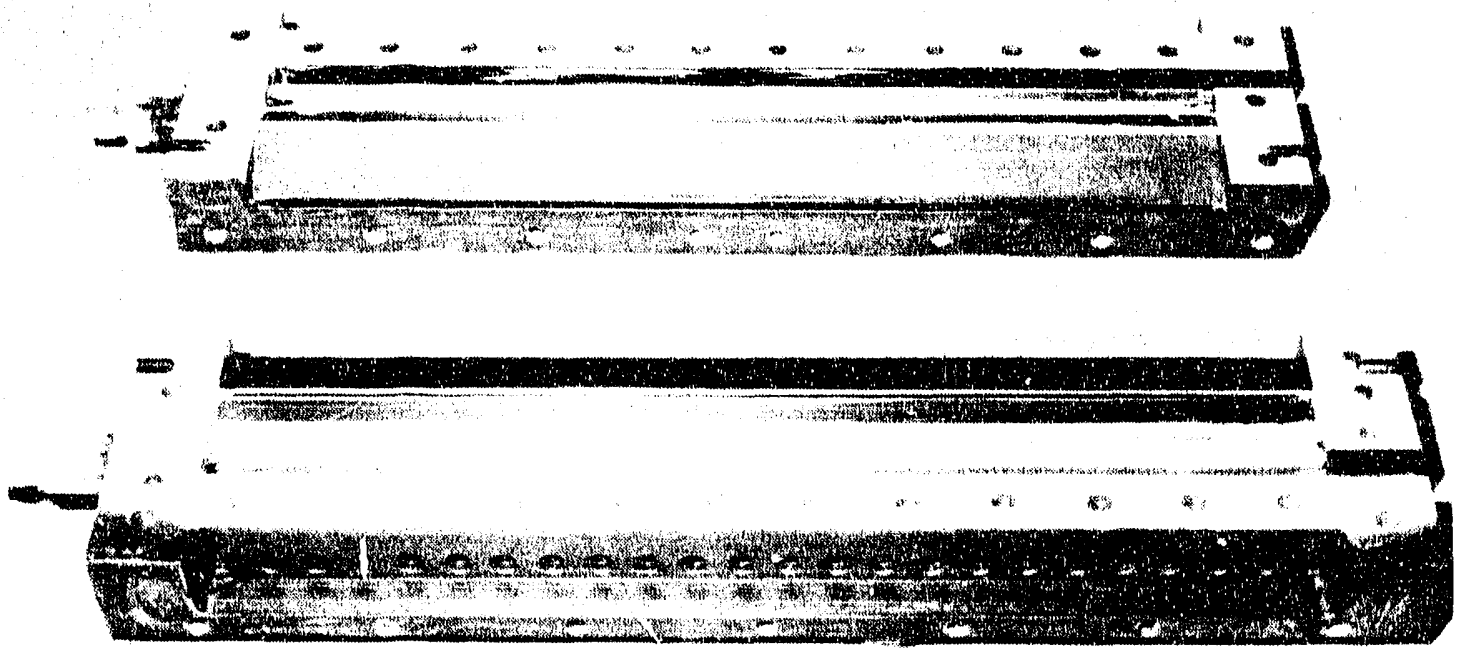

Figure 13. Internal view of impactor halves.

purge flow design for this impactor, the advantage of a coarse flow region that could be drawn uniformly across the entire lengtr of the curs inlet was sacrificed. Despite this, the impactor efficiency was determined at different coarse flow rates by drawing the coarse flow out the connectors at the end of the
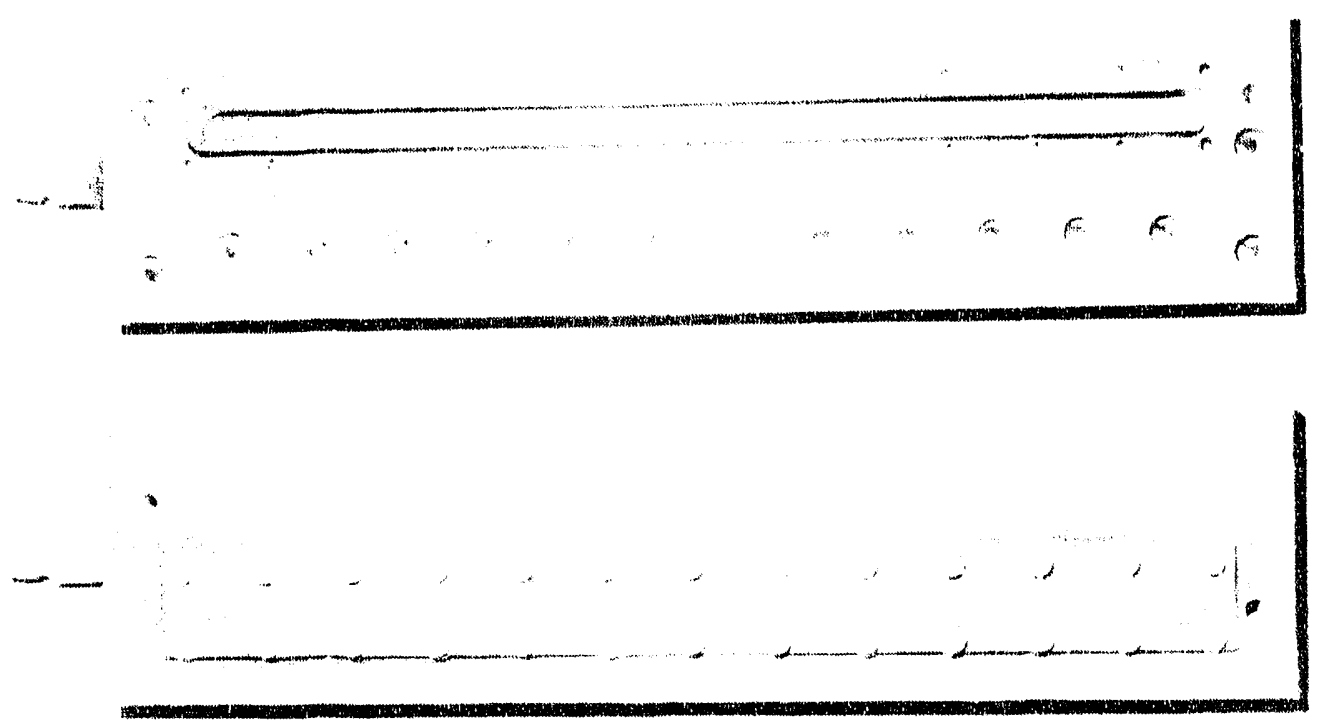

Figure 14. External view of impactor halves. 
impactor. Especially for coarse flows that are a significant percent of the total flow, the flow inside the cup would necessarily vary along its length, adversely affecting the cutoff characteristics. This impactor was built for a $1.0-\mu \mathrm{m}$ diameter particle cutoff which, according to the mathematical model for the collection system, gives the best signal-to-noise ratio. When tested, however, this impactor turned out to have a $1.5-\mu \mathrm{m}$ cutoff. The results (Figure 15) from the first impactor are encouraging in two respects: First, the efficiency is about as high (90\%) as can be expected when compared to performance of the existing virtual impactors. Second, the size resolution is about. as good as can be expected.

Figure 15 shows the test resilts for the purge flow impactor operated at a coarse flow rate of $10 \%$ of the total flow. The coarse flow is seen to have a transmission efficiency of $12 \%$ for small particles. A lower efficiency would be preferred, but $10 \%$ is the lowest theoretically possible, since the impactor was run at 10\% coarse flow. The figure indicates that for large particles, the efficiency rises to 90\%. A higher efficiency is possible, but in practice is usually not achieved for virtual impactors. It can also be seen

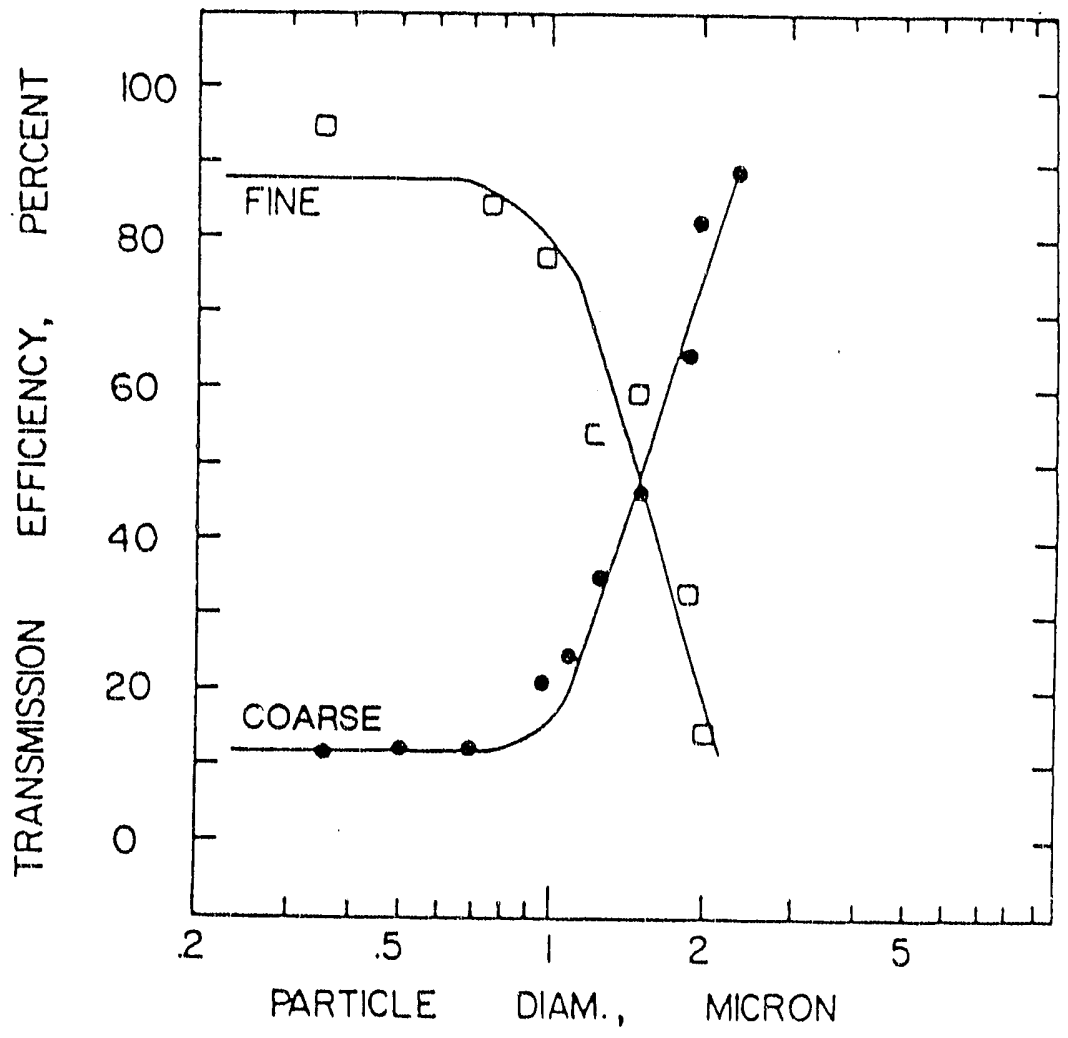

Figure 15. Efficiency curves for impactor shown above.

that the rise of

efficiency takes place over a factor of 2 diameter range, which is a typical size resolution for impactors. The efficiency of the fine flow seen in Figure 15 is what one would expect for the indicated coarse flow efficiency.

When the impactor was tested with a reduced coarse flow, equal to if of the total flow, the coarse particle efficiency was about 1 \% for small particles and $50 \%$ for large particles. When this 
performance was used as input to the mathematical model of the collection system, the model indicated that the impactor should be run at $1 \%$ coarse flow, because the resultant signal-to-noise ratio was better than for $10 \%$ coarse flow. This is because $1 \%$ contamination of the coarse flow by small particles decreases the noise (particles which should not be part of the chemical sample, but are in the sample), and this efiect predominates over the degradation of the collection efficiency of

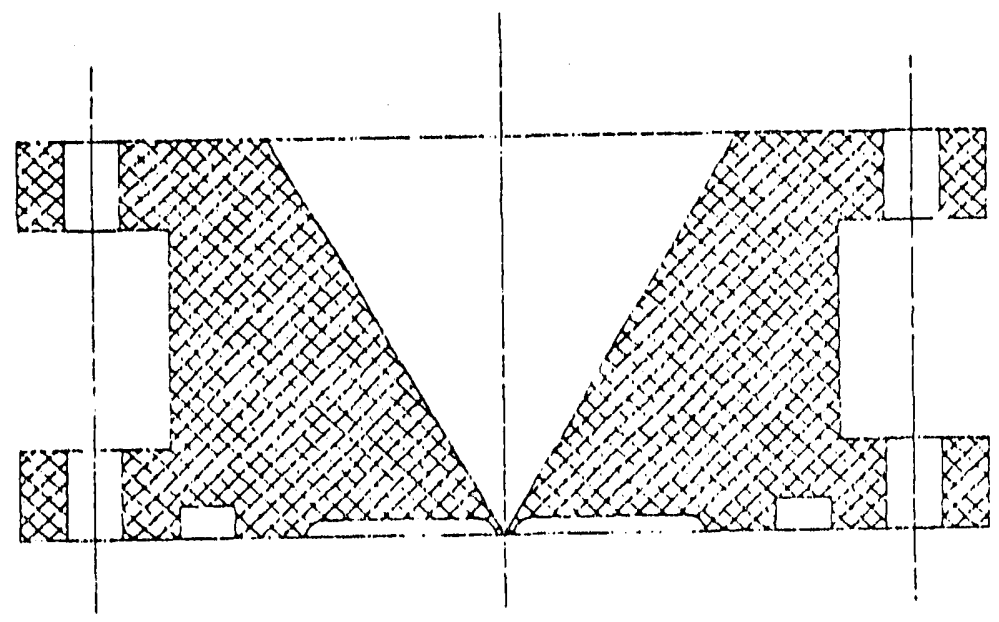

Figure 16. Cross section of impactor entrance section. big particles (degradation from $90 \%$ to 50\%).

\section{B. Improved Design}

The second impactor design is shown in Figure 3. It is made in several sections

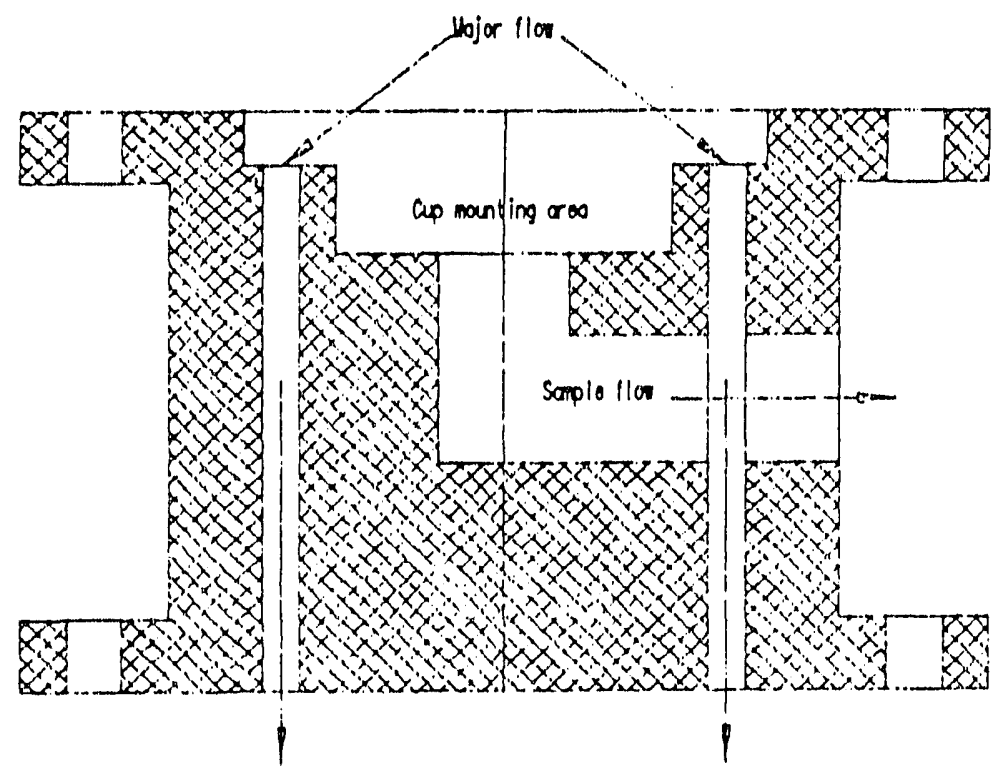

Figure 17. Cross-section view of base section.

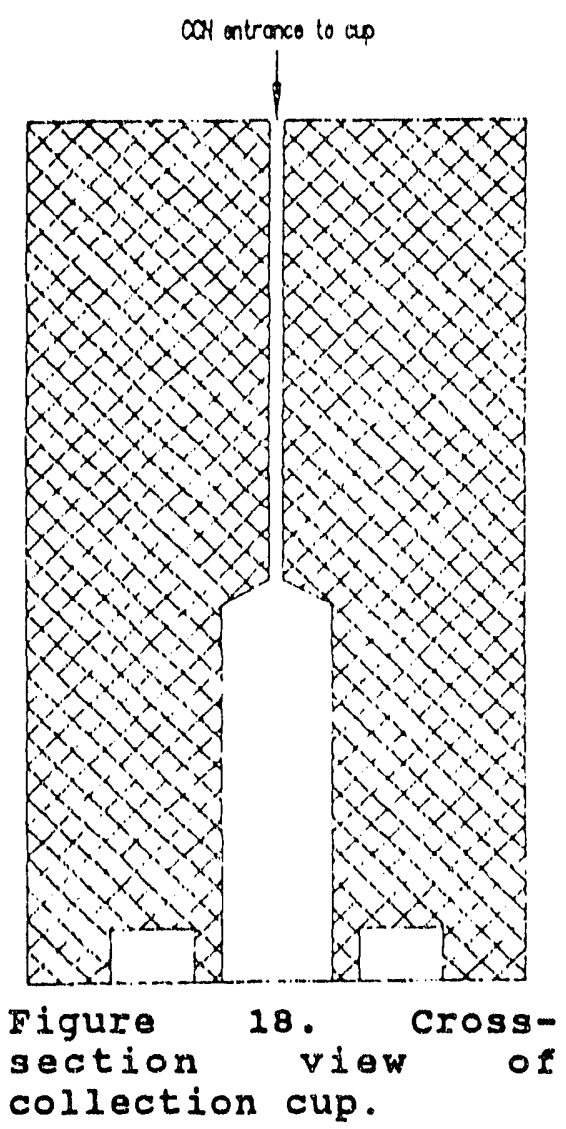


that fit together with o-ring seals (Figures 15-19). Impactors with very different cutoif characteristics can be made by replacing the inlet and cup sections. The base and the spacer sections can be virtually the same for the different impactor devices being constructed for the two CCN collection systems. A cross-section view of the entrance section is shown in Figure 16. The flow enters the top and is focused into the slit. For different cutoff designs, not only the slit width is changed, but also the thickness of the slit lips, and the distance from the cup inlet.

The impactor base section is shown in Figure 17. The major flow passes on through and out the side opposite the inlet. The outlet labeled "sample flow" comes from the coarse flow collection cup. There are six sample flow outlets along the base of the impactor (Figure 3), each corresponding to a partition in the cup, to improve the evenness of the coarse flow draw across the $12 "$ length of the cup slit length.

A cross section view of the cup is given in Figure 18, and a picture of one of the cup designs is shown in Figure 1.9. For the purge flow option, the cup has several special features. The cup has internal partitions, and each partition has its own outlet flow, in an attempt to reduce contamination of the purge flow by the inlet flow. The shoulder of the purge flow cup is flat, making the cup inlet essentially a slit in a flat plate.

Referring to Figure 18, this design leaves ample material near

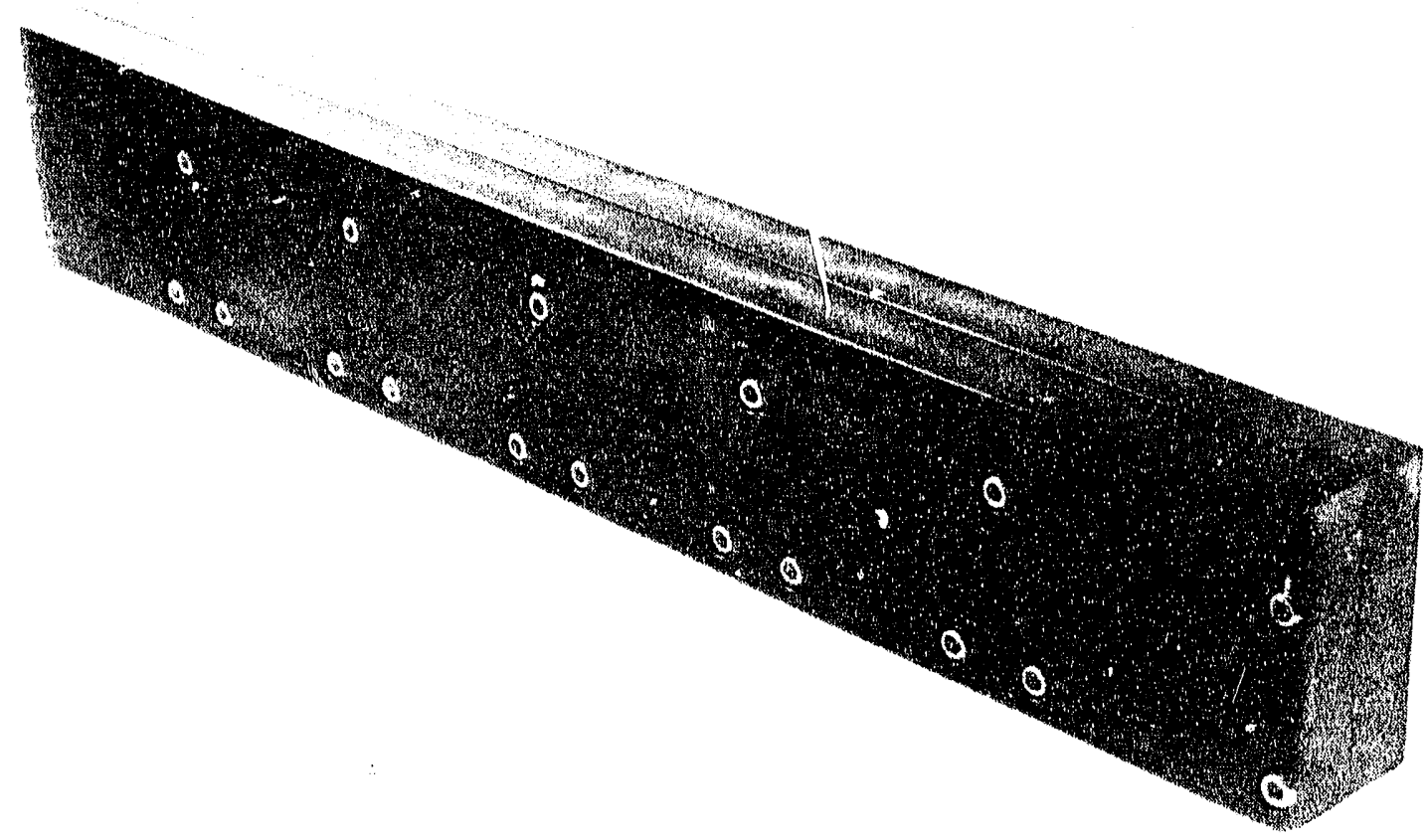

Figure 19. View of collection cup. 
the cup entrance to construct purge flow channels. The shoulders are removed for the $0.5-\mu \mathrm{m}$ cutoff impactors to streamline the flow and reduce particle loss.

An efficiency curve for

the $0.5-\mu \mathrm{m}$ cutoff

impactor is shown in

Figure 20. The points were taken during the course of different runs to evaluate the impactor performance, some of which were not ideal. The procedure that has evolved is to generate latex particles of a particular size, and draw them through the impactor at different flow rates to cover the appropriate stokes number range. After the impactor has been run for 8 to 10 hours, it is taken apart and examined for places where the particles collect. Appropriate changes are then made and the test repeated. In spite these procedures, the impactor cutoff appears

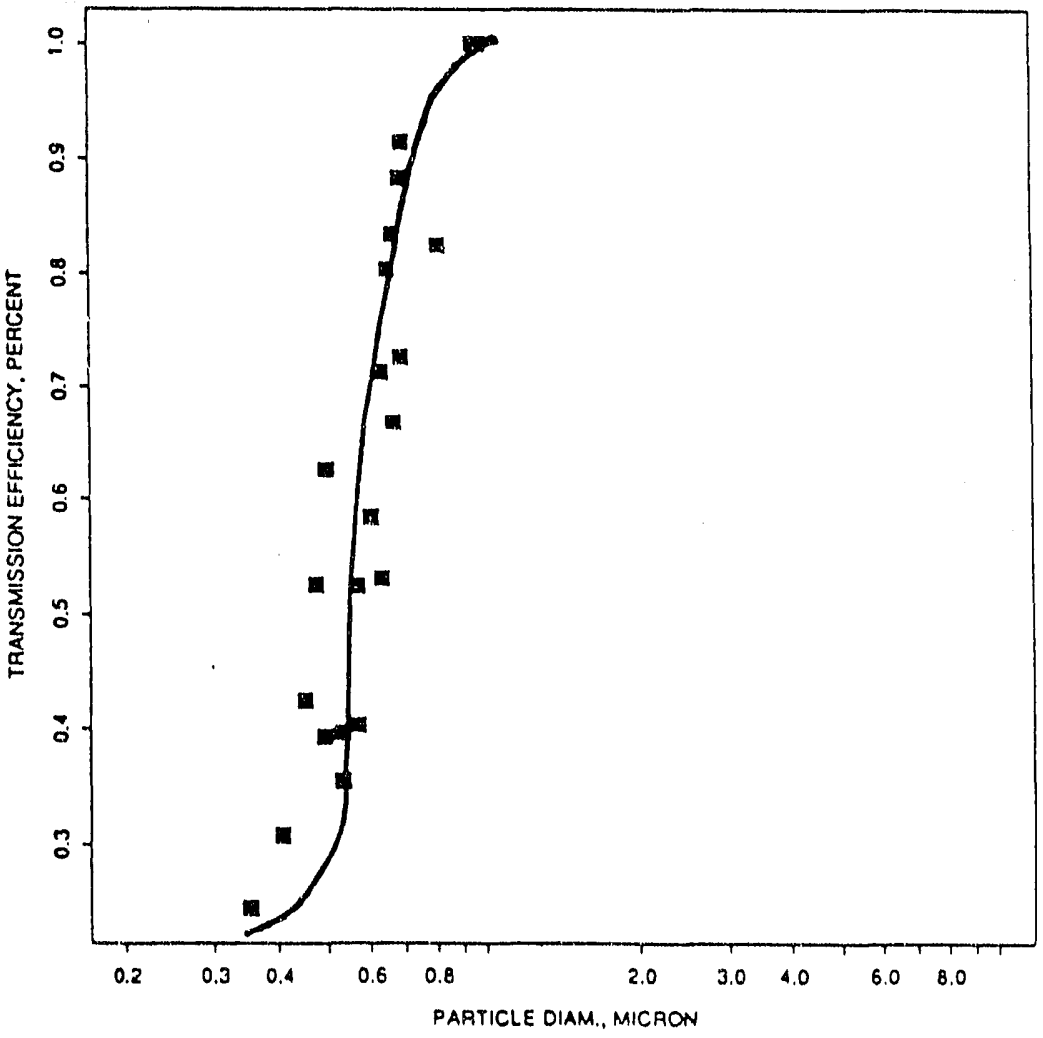

Figure 20. Efficiency curve for $0.5-\mu \mathrm{m}$ cutoff impactor. fairly sharp, and close to the desired cutoff of $0.5 \mu \mathrm{m}$.

\section{c. Purge Flow Modeling}

As an aid to impactor design, especially the purge flow concept, a fluid dynamics model is being used to evaluate different flows of interest. The model being used is a finite element code called FIDAP, which is widely accessible and is supported on the computer system at the University of Illinois. The geometry of the impactor is entered into the code, along with the fluid boundary conditions, and, when all goes well, the appropriately converged solution for the flow field is calculated. Only flow streamlines inside the collection cup are considered here, although flow in the whole impactor domain must be solved to determine these streamlines. 
Figures 21-24 show the fluid velocity streamlines inside the collection cup for several

different situations. only

a two-dimensional cross

section need be

considered, since,

ignoring end effects, the

flow should be uniform

along the length of the

slit. Further, the flow is

symmetrical about the

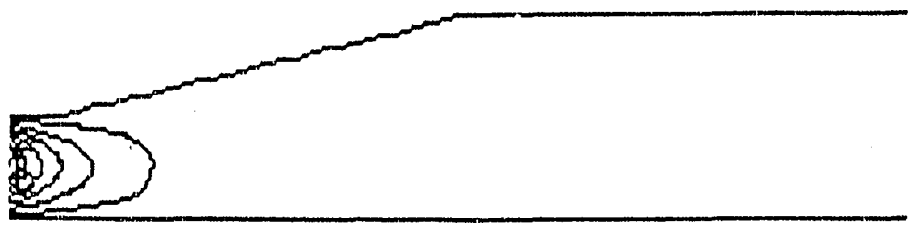

Figure 21. Zero-flow coarse-particle collection cup.

centerline of the cross

section. Figure 21 shows the streamlines in half of the coarseflow collection cup for a $1-\mu \mathrm{m}$ cutoff impactor with zero coarse flow. (By reflecting the figure about the bottom boundary, which is the stagnation streamline, the cross section of the cup is formed.) The streamlines show that the high-velocity jet from the impactor nozzle enters the cup, turns, and then exits. This is the region of the flow where the coarse particles, unable to follow the sharply turning flow because of their momentum, cross streamlines and are concentrated in the cup. In an irupactor with non-zero coarse flow, a portion of the incoming flow would transit the cup carrying entrained fine particies that would contaminate for the $C C N$ collection system. Figure 21 suggests the plausibility of a zero-flow cup as the collection medium. The coarse particles, droplets

containing $\mathrm{CCN}$, would concentrate inside the cup for the duration of the experiment. The cup would be removed, and the sample washed from the suriaces of the cup.

Figure 22 shows the streamlines in the same cup geometry with a purge flow entering at the top and flowing toward the right-hand end of the cup. A small eddy sets up between the entrance of the purge flow and the major flow at the mouth of the cup. The fate of $C C N$ captired in the eddy is not clear. Part of them would probably be entrained back into the major flow, part entrained inte the purge flow, and part would attach to the walls in the throat of the cup. A considerable part may even remain trapped in the eddy, raising the question of how to turn the collection system off without losing that part of the sample.

In Figure 23 the purge flow inlet is moved closer to the mouth of the cup. In this case, some of the purge flow follows the major flow, while a part of the majo: flow, with entrained small. particles, enters the purge flow. The purge volumetric flow was 
about 1 of the total flow, and only about $0.01 \%$ of the major flow entered the cup. The model thus predicts that the fine-particle contamination of purge flow would be 1000 times smaller than a conventional design with 10 \% coarse flow. A smaller eddy than before would again set up between the two regions, although not enough streamlines were plotted to show this feature.

The geometry of the cup shown in Figure 24 is different in that the width of the cup does not increase over its dimension at the mouth. The distance of the purge outlet from the impactor mouth and the width of the outlet silt are the same as the cup width $(0.060 ")$. (The

vertical scale in this figure is expanded over that in Figures 21-2.3, but the general impactor dimensions and major flow rate are similar.) The purge flow for this model experiment enters at the end of the cup at the right-

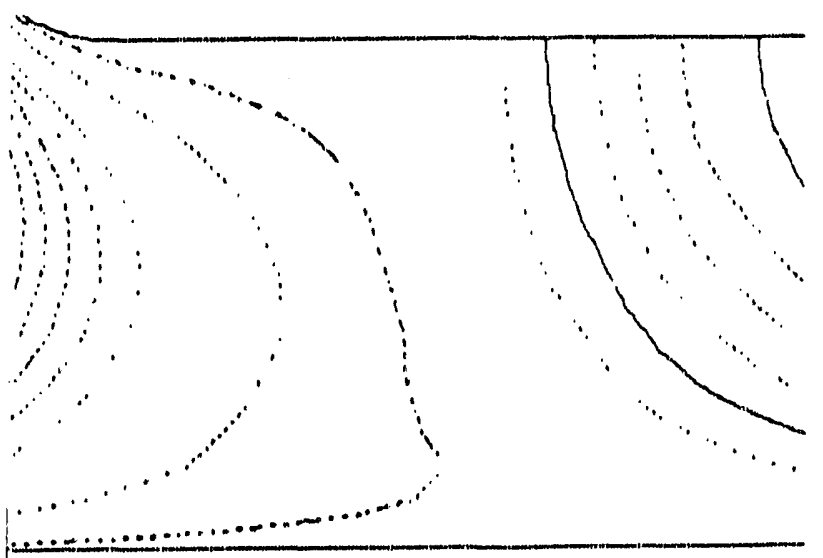

Figure 24. purge-flow cup with purge llow entering at right and exiting at top. hand side, and exits at the top

of the cup. The purge flow is both reversed in direction, and increased to about $10 \%$ of the major flow. The situation is similar in appearance to an opposing flow virtual impactor. However, if the purge flow were turned off, the streamiines would be like those in Figure 21; thus the purge flow in this example is not responsible for the essential impactor separation function. With the purge flow in this direction, the shear region where the flows meet is much less intense than in the above examples, so no eduy forms. It appears that the purge flow shapes the major flow in such a way as to sharpen the cutoff, since the streamiines of the major flow become less rounded where the flows meet. This purge flow design is presently being constructed and will soon be tested.

\section{Automated CFD Cloud Chamber}

The automated CFD cloud chamber will be used to measure the critical supersaturation spectrum of the atmospheric particles 
after they have passed through an electrostatic classifier during the field experiments. Such measurements have been used in the past (Alofs, Hagen, and Trueblood, 1989) to determine information about chemical composition. It will also be used to estimate how long the chemical collection system should be run to collect sufficient sample. This instrument is an automated version of the manual CFD cloud chamber that has been used at the University of Missouri-Rolla for many years (Alofs, 1978). The development work on the new device is a routine endeavor with only low risk of unforeseen difficulties. Flows in the manual CFD cloud chamber are changed by adjusting valves in an iterative procedure while watching flow meters and pressure gages. Flows in the automated CFD cloud chamber are changed using automatic flow regulators, which get their set point either from a computer or from the output of pressure transducers. Temperatures are changed using thermal baths, which have temperature controllers that receive their set point from the computer. The automated CFD cloud chamber will save considerable human effort and operator training.

\section{Discussion}

Construction and individual testing of the several components of the CCN collection system is nearing completion. Problems wi.th the haze chamber plate-wetting appear to be satisfactorily solved. Testing of the haze chamber plate temperature regulation with the preheater is the main remaining uncertainty. The CFD cloud chamber cold-plate temperature regulation works satisfactorily. Successful operation of the hot plate is the next milestone, but no major problems are expected. The latest design of the $0.5-\mu \mathrm{m}$ cutoff impactor looks promising, and after a few more tests, four identical copies will be machined (two for each of the two versions of the collection system being constructed). The purge flow design needs more evaluation before the final decision is made on whether the concept is acceptable. However, the option of zero coarse flow, with sample collection inside the cup, is an acceptable alternative if the purge flow design does not work.

of course, operating the system as a single unit is the most critical test. The question of whether the impactors will activate additional nuclei remains a matter of experimental determination, although our modeling efforts indicate this is not a serious problem. The most important determination to be gained from the testing of the system is to see if contamination from the various surfaces of the system can be made small enough. An additional important question is to determine whether the small $C C N$ size fraction car be collected without contamination from larger particles. The tests to be performed are simple and reliable, so definite answers can be obtained. Filtered air containing virtualily no $C C N$ can be drawn through the system for 
long periods of time to determine the level of background contamination. Particles of sodium chloride and of ammonium sulfate can be generated, and a monodisperse size selected with a classifier to test the ability of the system to separate the different dry diameter sizes of soluble particles. other similar tests with non-soluble particles of different wettability are also planned.

Construction of the second version of the haze chamber and CFD cloud chamber, which are to be placed in the trailer for field use, is well under way. Both frames and the cold plates have been constructed. The laborious drilling and tapping of the hundreds of holes to secure the outer plates to both chambers has been started. With the major problems solved in constructing the first version, the second version is much less a research effort and should be completed shortly after the first version is tested.

\section{References}

Alofs, D. J., 1978: Performance of a Dual-Range Cloud Nucleus Counter. J. Appl. Meteor., 17, 1286-1297.

Alofs, D. J., D. E. Hagen, and M. B. Trueblood, 1989: Measured Spectra of the Hygroscopic Fraction of Atmospheric Aerosol Particles. J. Appl. Meteor. 28, 126-136. 
x. Appendix A

Paper presented at the Fiftly International conference on Precipitation Scavenging and Atmospheric-surface Exchange Processes held at Richland, WA July 15-19, 1991. The paper will be included in the proceedings which is in press. 


\section{DETERMINING THE CHEMICAL COMPOSIYION OF CLOUD CONDENBATION NUCLEI}

Allen L. Williams, Darryl J. Alofs", Donald E. Hagen", Daniel R. White*, A. R. Hopkins", and Max B. Trueblood*

Illinois state water Survey, 2204 Griffith Dr., Champaign, II 61820

"Cloud and Aerosol Science Laboratory, University of Missouri-Rolla

\section{Abstract}

This paper describes the design of a system to collect and chemically analyze cloud condensation nuclei (CCN). The basic approach is to identify which of the ambient aerosol particles are $C C N$ by their ability to form droplets under supersaturated conditions, and to selectively remove the nucleated CCN from the background aerosol based on the inertial properties of the droplets formed. Design criteria and supporting discussion are advanced for the continuous flow diffusion chamber (CFD), the haze chamber, and the virtual impactors to be used in the experiments. Arguments are presented showing why the $C C N$ sample must be divided into at least two parts for representative chemical analysis. Calculations are presented showing the behavior of a typical ambient aerosol as it passes through the collection system.

\section{INTRODUCTION}

The only known method of determining the subset of atmospheric aerosol that act as CCN from a given ambient sample is to expose the sample to a supersaturated environment. The particles that form droplets at the cloud level supersaturations are $C C N$. once activated the droplets will grow by diffusion in a supersaturated environment reaching, for example, $2.5 \mu \mathrm{m}$ diameter in 1 second at 1\% supersaturation. The $C C N$ can be identified through their inherent ability to form droplets, and the droplets, once formed, quickly grow to large enough sizes that they can be removed from the ambient aerosol.

Important questions relating to the experimental design of $C C N$ collection equipment involve the rate of $\mathrm{CCN}$ mass collection, and the ability to directly measure the composition of those CCN that are responsible for a large fraction of cloud droplets formed. An approximation of the size and mass distributions of the ary CCN particles can be made assuming that the spectrum, the number concentration of droplets, $N$, formed at critical supersaturation $S_{c}$, varies according to Twomey's relation' as

$$
N=N_{0} S_{c}^{1 / 2}
$$

Assuming there are 1,000 particles nucleated at $S_{c}$ of 1 pedcent, $N_{0}$ becomes $1000 / \mathrm{cm}^{3}$. The Kohler equations yield the critical supersaturation of dry $\mathrm{NaCl}$ particles to vary as 


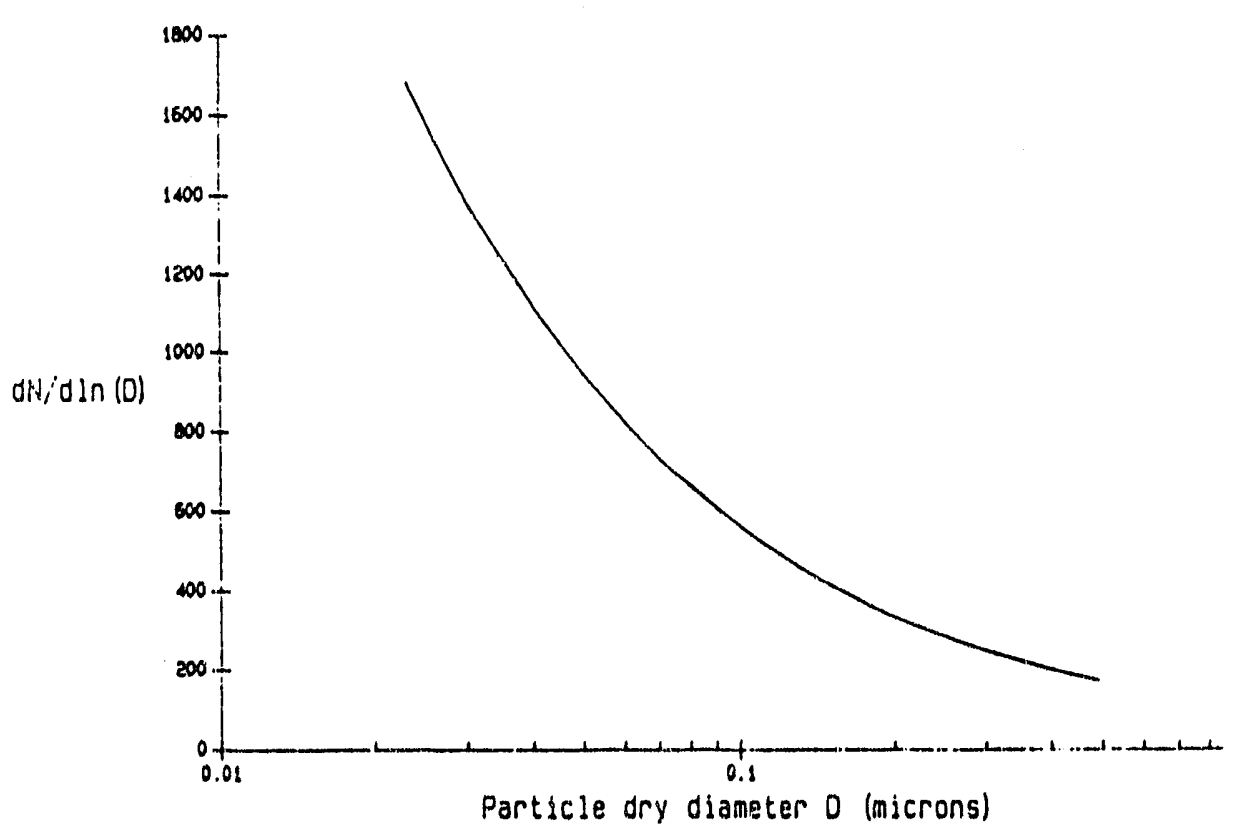

Figure 1. Number distribution of dry $C C N$ particles derived from the droplet spectrum. The area under the curve is proportional to the $\mathrm{CCN}$ number concentration.

$$
D=0.0232 S_{c}^{-2 / 3}
$$

where $D$ is the dry particle diameter in microns. Combining these expressions gives $N$, the number of $C C N$ with dry diameter greater than D;

$$
N=\frac{59 \cdot 4}{D^{3 / 4}}
$$

The resulting log-radius distribution is plotted in figure 1 , and the corresponding log-mass distribution is plotted in figure 2 .

In this example there are 941 particles $/ \mathrm{cm}^{3}$ below $1 \mu \mathrm{m}$ diameter, which represents a mass concentration of $20.75 \mu \mathrm{gm} / \mathrm{m}^{3}$. Seventy-one percent $(70.7 \%)$ of these particles are below $0.1 \mu \mathrm{m}$ diameter, and they account for only $0.112 \mu \mathrm{gm} / \mathrm{rm}^{3}$ or 0.548 of the mass. In a cloud with a peak supersaturation of $1 \%$, this example shows that most of the CCN would be from particles less than $0.1 \mu \mathrm{m}$ diameter. The larger particles, representing over 99 of the mass, would completely determine the chemical composition of the CCN if they were all collected together.

From the standpoint of the effects of $\mathrm{CCN}$ on cloud radiation, it is the number of cloud droplets formed that is of most significance. The nucleus in effect increases in size by a factor of hundreds as 


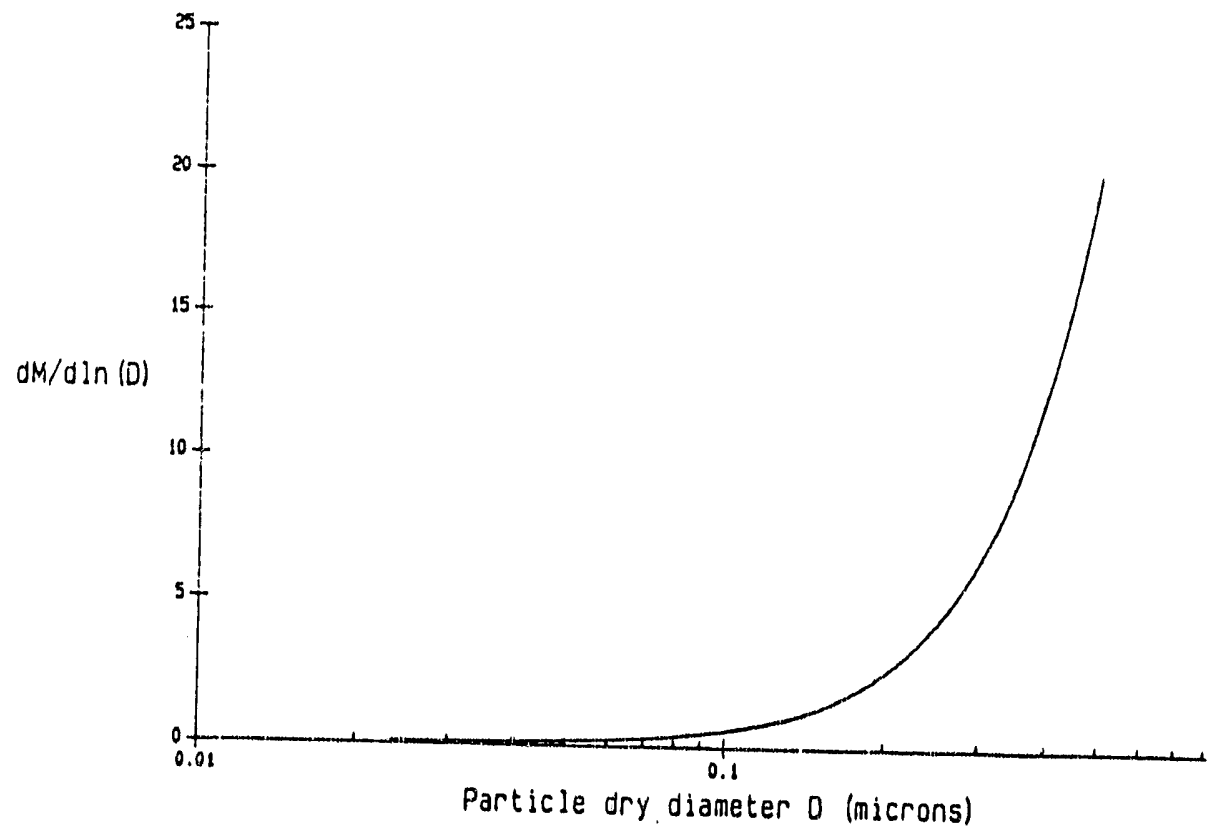

Figure 2. Mass distribution of dry CCN particles derived from the droplet spectrum. The area under the curve is proportional to the CCN mass concen'tration.

a cloud droplet is formed, and the $C C N$ particles are changed from an invisible subset of the atmospheric aerosol to a dominant feature that reflects incident sunlight. Except for clouds with low peak supersaturations, it is the very small CCN particles that substantially determine the number of droplets formed. It is apparent that the small $\mathrm{CCN}$ must be collected and analyzed separately from the larger $C C N$ particles. The sampling system being described here will separate the incoming sample into both a small CCN sample active at $0.16 \% \leq S_{c} \leq 1 \%$ (dry NaCl diameter below 0.1 $\mu \mathrm{m})$, as well as a large $C C N$ sample for nuclei active at $S_{c}<0.16 \%$ (dry NaCl diameter between $0.1 \mu \mathrm{m}$ and $0.5 \mu \mathrm{m}$ ).

If, as indicated in the above example, the small CCN are present in concentrations of order $0.1 \mu \mathrm{gm} / \mathrm{m}^{3}$, it would be necessary to sarnple between $10 \mathrm{~m}^{3}$ and $100 \mathrm{~m}^{3}$ of air to obtain enough mass for chemical analysis. The flow rate contemplated is $1,332 \mathrm{lpm}$, so $10 \mathrm{~m}^{3}$ of air could be sampled in 7.5 minutes, while $100 \mathrm{~m}^{3}$ could be sampled in 1 hour and 15 minutes. The corresponding large CCN amounts collected during these sampling times would be $42 \mu \mathrm{gm}$ and $420 \mu \mathrm{gm}$ respectively.

\section{APPARATUB}

The CCN mass collection system, as shown in figure 3 , consists of a series flow arrangement with a virtual impactor, followed by a haze chamber, another virtual impactor, a continuous flow diffusion 


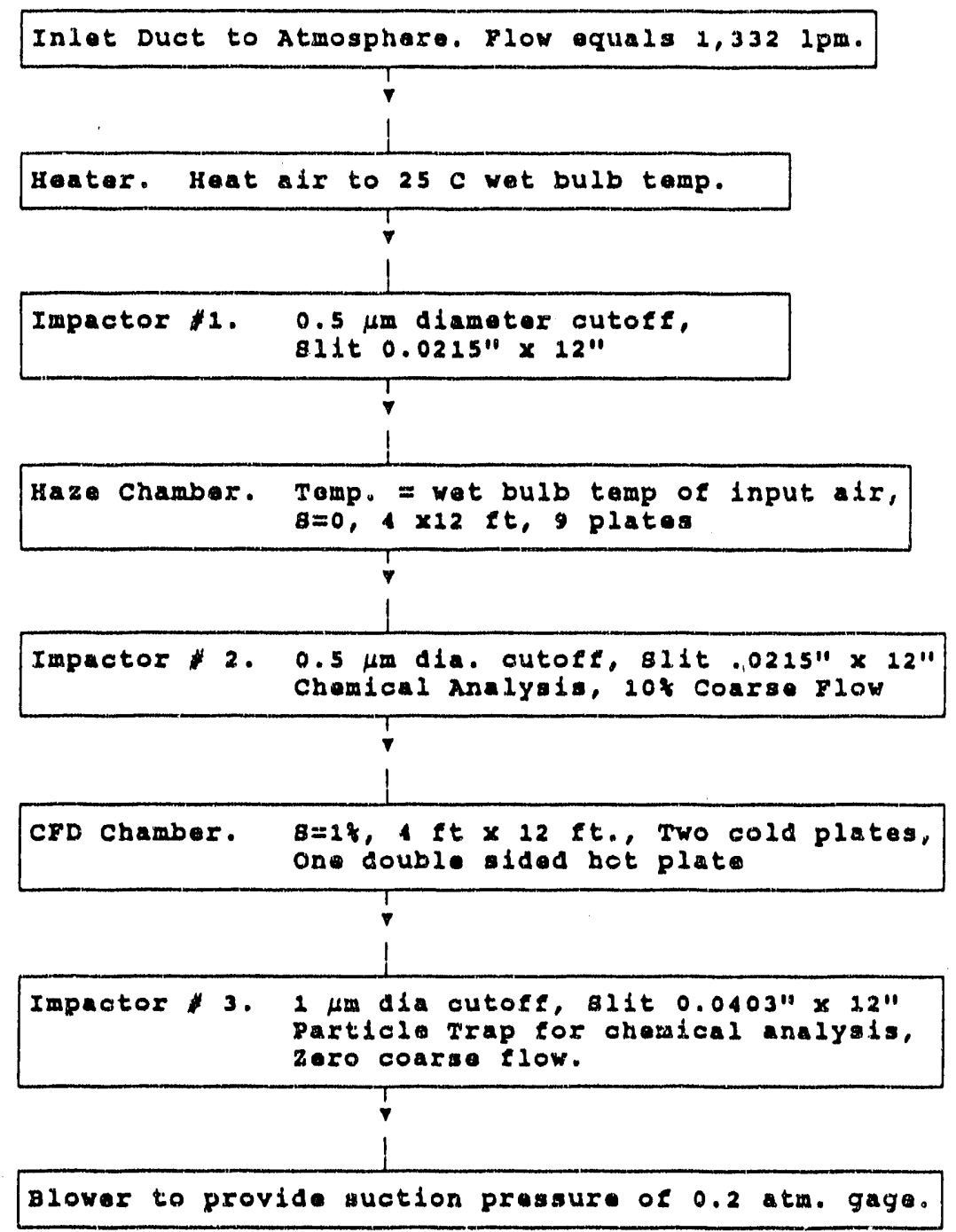

Figure 3. Components of $\mathrm{CCN}$ mass collection system.

chamber, and a final virtual inpactor. Ambient air is first heated so that, upon leaving the haze chamber, it will be at the ofr-cating temperature of the CFD. The air then passes through the first virtual impactor, which operates at a cutoff size of $0.5 \mu \mathrm{m}$. The fine particle flow of the first impactor passes into the haze chamber, where the particulate soluble material has time to absorb water and attain an equilibrium size. Aerosol particles exiting the haze chamber with sizes above $0.5 \mathrm{microns,} \mathrm{which} \mathrm{includes} \mathrm{particles}$ with dry diameter down to about $0.1 \mu \mathrm{m}$, are collected in the coarse flow of a virtual impactor for analysis as the large particle CCN. The remaining aerosol is passed into the CFD operating at near $1 \%$ supersaturation. The activated droplets are grown in the CFD to form micron-sized cloud droplets that are removed by the third 
virtual impactor to become the small particle CCN sample. The final impactor is operated in a zero coarse flow condition to eliminate the mixing of inactivated fine aerosol with the small particle $C C N$ sample.

\subsection{Continuous Flow Diffusion Chamber}

The volumetric flow of the entire system is essentially set by the flow capacity of the CFD. A rate of $1332 \mathrm{lpm}$ is attained by building the CFD to stand $4 \mathrm{ft}$ high and to flow horizontally along a 12 ft length. The design actually consists of two CFDs run in parallel. The outer walls are water cooled, and both are held at the same temperature by a single water bath. The inner common wall is electrically heated. The residence time of the sample in the CFD equals the time necessary for the supersaturation to reach its equilibrium value, plus the time to nucleate and grow the droplets to super-micron sizes. The latter time is approximately one second for cloud conditions. Considering a parallel plate construction for the CFD, a plate separation of about $0.8 \mathrm{~cm}$ is optimum to maximize the volumetric flow per unit plate area. For smaller plate spacing the volumetric flow decreases, and for larger separations the time for the supersaturation to reach its final value becomes a large part of the total residence time in the chamber. The optimum total volumetric flow per unit plate area is about $150 \mathrm{lpm} / \mathrm{m}^{2}$. Under these circumstances slightly over half the residence time is required for the supersaturation to equilibrate, so droplet nucleation and growth occur predominately in the latter half of the chamber. The sample entering the CFD, after leaving the haze chamber and passing through the second virtual impactor, should contain only $\mathrm{CCN}$ with a critical supersaturation above about $0.16 q$.

\subsection{Haze Chamber}

Large $C C N$ are separated from small $C C N$ using a steady flow haze chamber with a virtual impactor at the exit. This function depends on the laktionov ${ }^{2}$ relation

$$
D_{0}=\frac{.08}{S_{c}}
$$

where $D_{0}$ is the equilibrium size of the nucleus at 1008 relative humidity, and $s_{c}$ is the nucleus critical supersaturation. Thus with a $0.5 \mu \mathrm{m}$ diameter impactor cutoff, nuclei with $\mathrm{s}_{c}$ below $0.16 \%$ can be separated.

Since the virtual impactor proceeding the haze chamber removes all particles greater than $0.5 \mu \mathrm{m}$, the residence time in the haze chamber must be sufficient for nuclei with $D_{0} \leq 0.5 \mu \mathrm{m}$ to grow to at least $0.5 \mathrm{~mm}$ diameter. To match the flow of the CFD, and allow time for the droplets to reach their equilibrium size, 860 square 
feet of wetted surface is required. The haze chamber will be 4 ft by $12 \mathrm{ft}$ in dimension, and will consist of 9 parallel racks of wetted plates in a parallel plate configuration with a $1 \mathrm{~cm}$ spacing.

The haze chamber design has the simplicity of adiabatic cooling of the plates, thus avoiding the complication of active thermal control. Evaporative cooling of the plates by incoming sample air is compensated by the sensible heat transfer to the inlet air. As a result, the plate temperature equals the wet bulb temperature of the incoming air. An analysis by sparrow and Chen ${ }^{3}$ shows that such plates are very nearly isothermal. This is important in damping spurious supersaturations that could result if temperature gradients occur along the plates. During operation the inlet air to the haze chamber is merely heated to raise the wet bulb temperature of the sample air to the desired CFD inlet temperature.

\section{3 virtual Impactors}

Virtual impactors with cutoff sizes of $0.5 \mu \mathrm{m}$, before and after the haze chamber, and a cutoff of $1 \mu \mathrm{m}$ following the CFD are required. The operation of virtual impactors has received considerable attention (e.g., Marple and $C h i e n^{4}$ ) and is well characterized. The cutoff efficiency varies as the square root of the dimensionless stokes number, sk, which can be written as

$$
S k=\frac{\rho V C D^{2}}{9 \mu W}
$$

where $\rho=$ the particle density, $V=$ the nozzle velocity, $c=$ the Cunningham slip factor, $D=$ the particle diameter, $\mu=$ the fluid viscosity, and $w=$ the nozzle diameter. The cutoff diameter can be found by solving equation 5 for $D$ after setting $s k=0.49$. By changing the nozzle diameter and flow velocity, the cutoff size can be adjusted over a considerable range.

The pressure drop through the impactor is an important parameter from the standpoint of the present application, since a single vacuum pump must draw the sample through all three impactors as well as the haze chamber and the CFD. The pressure drop across an impactor varies as $V^{2}$, so designs that operate at small values of $\mathrm{V}$ are preferable. A 12 in. long slit design for the impactors has been chosen, with the slit width and other dimensions varied to obtain the two cutoff sizes required. Recommendations from work by Chen and Yeh ${ }^{5}$ are incorporated to lower the particle attachment to the impactor walls. A $12 \mathrm{in}$. slit with $0.108 \mathrm{~cm}$ spacing appears satisfactory for the $1 \mu \mathrm{m}$ cutoff impactor, while the $0.5 \mu \mathrm{m}$ impactors will consist of a $0.055 \mathrm{~cm}$ slit spacing.

The $0.5 \mu \mathrm{m}$ cutoff inpactors will operate with a filter in the 
coarse flow region, through which a small fraction of the total flow will be drawn. The filter from the impactor exiting the haze chamber represents the large $C C N$ sample and will be kept for analysis. Sample air flow through the coarse flow region of the final impactor will be maintained at zero in order to reduce contamination in the small $C C N$ sample. The droplets will be inertialiy separated into the dead air space, just as with a conventional virtual impactor with a non-zero coarse flow. Tests are being conducted to determine if the sample volume can be flushed from the dead air space without altering the impactor cutoff efficiency, or causing background air and associated contaminants to be mixed in the sample air.

\section{DIBCUSBION}

The capability of the haze chamber for separating the large and small $\mathrm{CCN}$ can be demonstrated for a particular case. Assume the aerosol entering the system has the shape of a Whitby distribution of soluble particles. From the Kohler equation the critical supersaturation for each dry particle size can be determined, and the resulting distribution is shown in curve 1 of figure 4 . Here $\Delta N / \Delta \ln \left(S_{c}\right)$, the change in the number concentration, $N$, with respect to a change in logarithm of the critical supersaturation, $S_{f}$ is plotted versus $\ln \left(S_{c}\right)$, so the area under the curve represents the total particle concentration. For the flow rate of $1,332 \mathrm{lpm}$ of the $C C N$ collection system, the rate at which mass enters the system can be found for the assumed Whitby distribution, and is plotted in curve 1 of figure 5 . This represents the number and mass that enters the first impactor. The particles that pass through the fine particle section of the first virtual impactor would be exposed to the

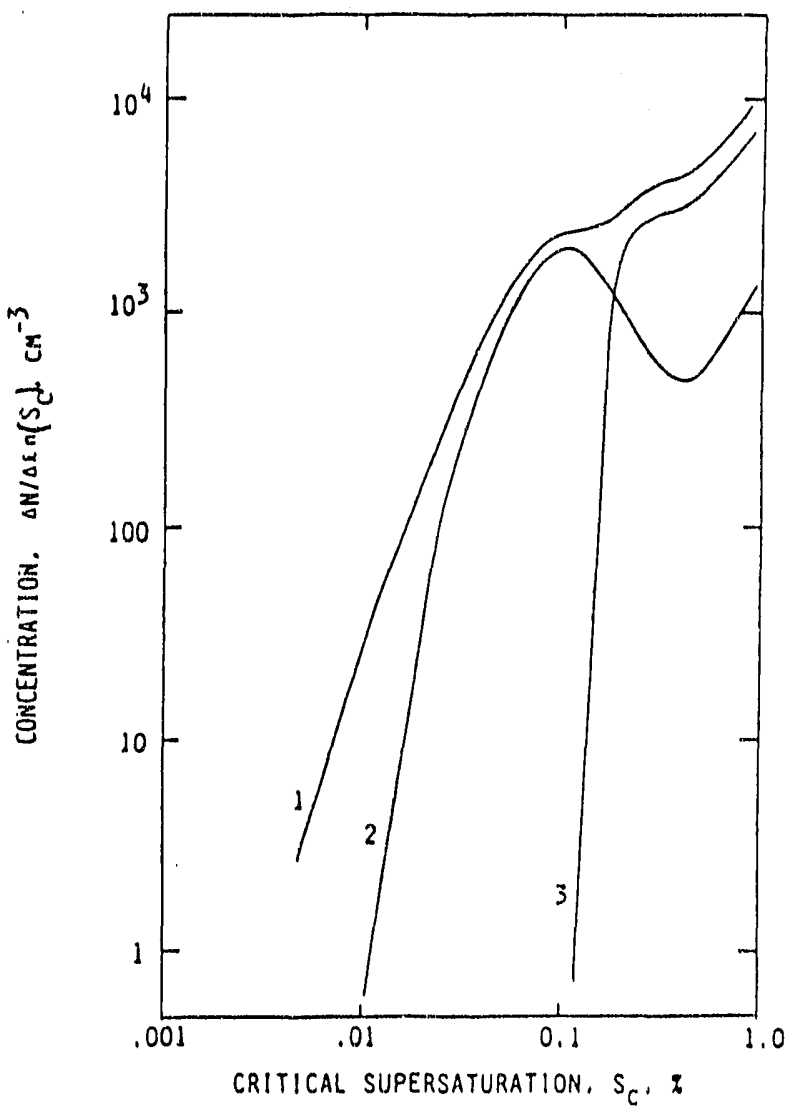

Figure 4. Log-supersaturation number distribution.

Curve 1: Into first impactor, Curve 2: Into second impactor, Curve 3: Into CFD chamber. $100 \%$ humidity environment of the haze chamber, and would reach their equilibrium sizes. The droplet concentration and particle mass flow rate that would be removed into the filter of the coarse flow region of the second virtual 
impactor are shown in curve 2 of figures 4 and 5 respectively. This corresponds to the large $C C N$ sample. The droplets and particles separated into the fine flow, and therefore passing into the CFD, are shown in curve 3 of each figure. Since not all of the particles passing into the CFD would be activated, curve 3 in each of the figures represents an upper limit to the small CCN sample. Comparison of the area under curves 2 and 3 of figure 4 shows that the small CCN represent larger numbers of particles than the large CCN. Similarly, the area under curves 2 and 3 of figure 5 shows that the large $C C N$ account for more of the mass. If the second impactor cutoff were $1.5 \mu \mathrm{m}$ instead of $0.5 \mu \mathrm{m}$, so that CCN with dry diameter between $0.2 \mu \mathrm{m}$ and $0.5 \mu \mathrm{m}$ rather than between $0.1 \mu \mathrm{m}$ and $0.5 \mathrm{\mu m}$ were collected in the filter of the second impactor, the rate of mass collection of small $C C N$ would be increased by a factor of 3 .

The equilibrium supersaturation and fluid velocity profiles across the CFD have nearly parabolic shapes, so particles close to the walls experience a lower supersaturation and stay in the chamber longer. Also, during equilibration the supersaturation close to the hot plate is lower, and that near the cold plate higher, than the final equilibrium values. Considering these effects the droplet growth inside the CFD can be calculated. Assuming the particles first attain their equilibrium size in the haze chamber, only those haze droplets with sizes greater than $.5 \mu \mathrm{m}$ are allowed to pass into the CFD. Figure 6 shows the Eraction of these that enter the CFD and are able to reach at least the specified cutoff size for different $S_{c}$. The 4 curves having different cutoff sizes

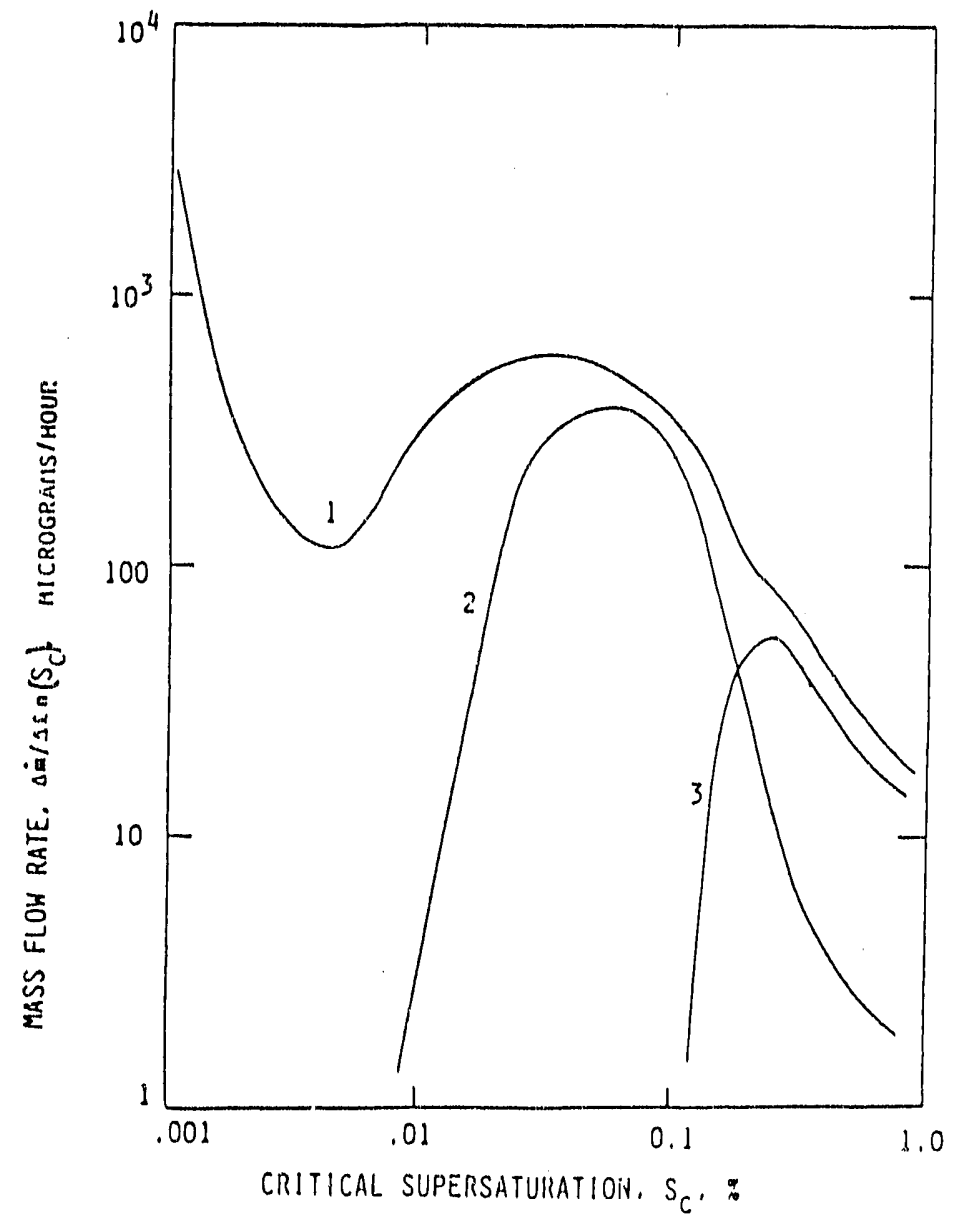

Figure 5. Log-supersaturation mass distribution. Curve 1: Into first impactor, Curve 2: Into second impactor, Curve 3: Into CFD chamber. 


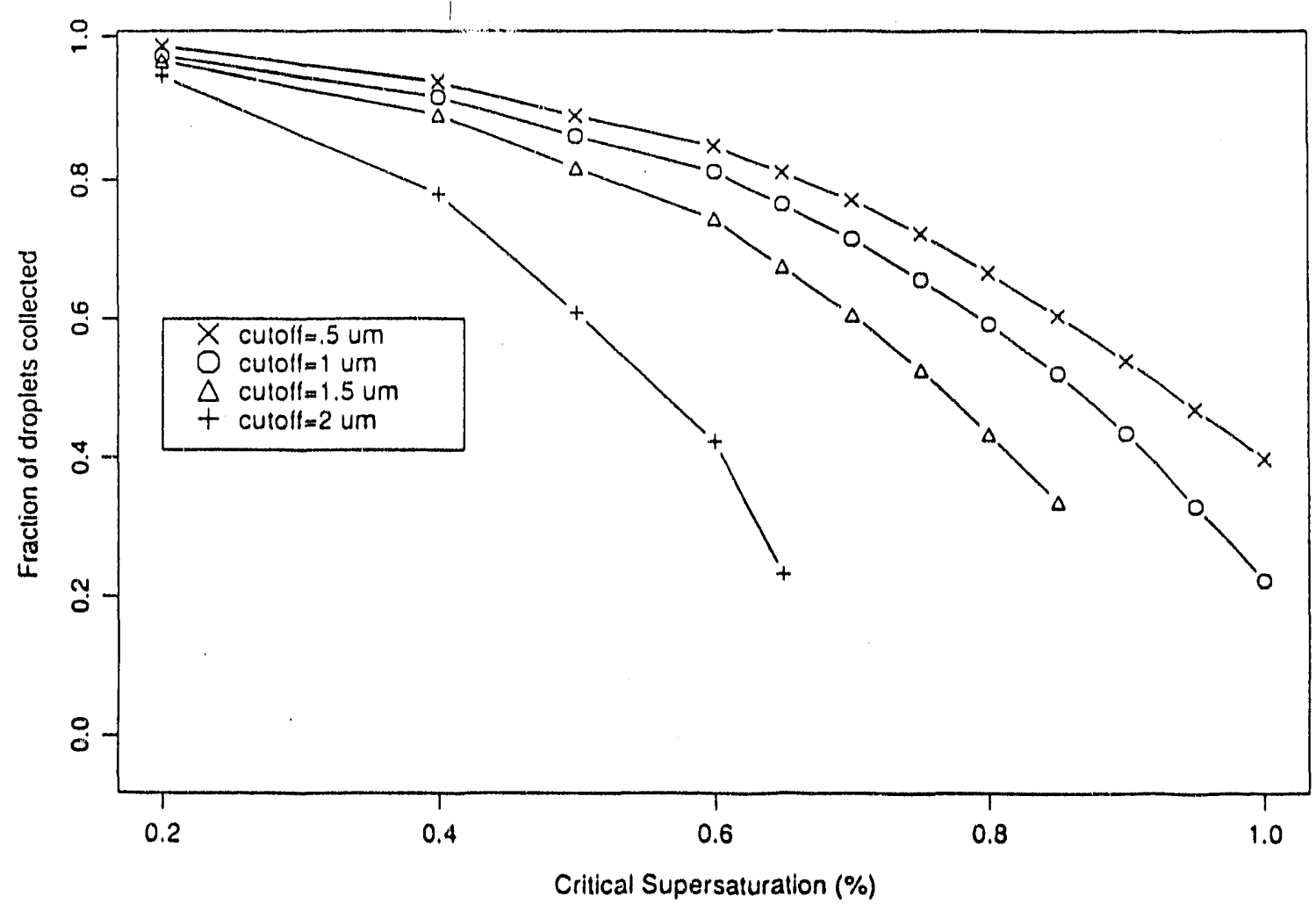

Figure 6. Fraction of particles as a function of critical supersaturation that would leave the CFD after attaining at least the final droplet size specified by each curve.

ranging from $.5 \mu \mathrm{m}$ to $2 \mu \mathrm{m}$ diameter represent approximately that fraction that would be collected as small $\mathrm{CCN}$ in impactors with the corresponding cutoff sizes. Lowering the impactor cutoff from $2 \mu \mathrm{m}$ to $1 \mu \mathrm{m}$ gives clear advantage, and operating at a cutoff of $.5 \mu \mathrm{m}$ looks feasible from this standpoint. Although the calculations assume a 18 peak supersaturation in the CFD, a slightly higher peak value would allow the collection of higher fraction of the particles with peak supersaturations near 18.

The use of virtual impactors to separate droplets from the background aerosol raises the question of nucleation inside the virtual impactor. The pressure drop inside the nozzle of a virtual impactor behaves, in effect, like an expansion cloud chamber and produces a supersaturation. Using a potential flow model to estimate the pressure and velocity fields inside an impactor nozzle, and assuming an adiabatic expansion of already saturated air, the peak supersaturations turn out quite high, being in the range of from $70 \%$ to $300 \%$ over typical impactor flow rates. However, the time that a particle is exposed to the high supersaturations is only of orcer $10 \mu \mathrm{sec}$. Particle or droplet growth could only increase sizes on the order of $10^{-3} \mu \mathrm{m}$ under these conditions, so this does not appear to be a problem. 


\section{CONCLUSIONB}

The CCN collection system described here is presently being built and tested. Calculations are presented to show the feasibility of collecting $C C N$ in sufficient enough quantities for chemical analysis. The argument is presented that $C C N$ in sizes less than approximately .1 $\mu \mathrm{m}$ diameter must be collected separately to prevent the larger $\mathrm{CCN}$ from dominating the composition of the sample. These constraints require a system with large flow rates and the capability of separating the $C C N$ into different categories depending on their critical supersaturation.

\section{Rererences}

1. Twomey, S. A., 1977: Atmospheric Aerosols, Elsevier, New York.

2. Laktionov, A. G., 1972: A Constant Temperature Method of Determining the Concentrations of cloud Condensation Nuclei, IzV. Acad. Sci. USSR, Atmos. Ocean PhyS., 8, 382-385.

3. Sparrow, E.M. and T. S. Chen, $1969 ;$ Mutually Dependent Heat and Mass Transfer in a Laminar Duct, A.I.CH.E.J., 15, 434-441.

4. Marple, V. A. and C. M. Chein, 1980: Virtual Impactors: A Theoretical study, Environmental Science and Technology, 14, 976-984.

5. Chen B. T. and H. C. Yeh, 1987: An Improved Virtual Impactor: Design and Performance, I. Aerosol Science, 18, 203-214.

6. Biswas, P. and R. C. Flagan, 1988: The Particle Trap Impactor, J. Aerosol Science, 19, 113-121. 
XI. Appendix B

Paper to be submitted to the Journal of Applied Meteorology.

linepient remeved 
